\title{
Análisis de técnicas de manufactura de alfarería prehispánica tardía en el Noroeste Argentino (siglos XIII-XVII d.C.). Una contribución del estilo Sanagasta/Angualasto del sito Tambería de Guandacol (provincia de La Rioja)
}

Sebastián A. Carosio*
Recibido:

8 de marzo de 2017

Aceptado:

31 de agosto de 2017

\section{Resumen}

En este trabajo se presentan los resultados sobre el estudio de las técnicas de manufactura involucradas en la producción alfarera del sitio Tambería de Guandacol, departamento de Felipe Varela, provincia de La Rioja (Argentina). Las piezas cerámicas se corresponden con el Estilo Sanagasta/Angualasto, asociado fundamentalmente a la época prehispánica tardía en el Noroeste Argentino (siglos XIII-XVII d.C.). A partir de un registro esencialmente fragmentario y mediante la combinación de estudios traceológicos y de petrografía cerámica, se pretende avanzar en el conocimiento de la cadena operativa y organización de la producción alfarera de los grupos que habitaron el valle durante dicho lapso. Asimismo se discuten los alcances y limitaciones de este tipo de estudio sobre registros fragmentarios. Los resultados han permitido registrar una elección uniforme de técnicas primarias y secundarias para la confección de recipientes y cierta irregularidad en los modos de aplicación. Igualmente, se reconocen semejanzas tecnológicas con producciones contemporáneas del área. El panorama permite plantear la existencia de un proceso de fabricación generado por un mismo grupo comunitario, con diferentes agentes involucrados y enmarcados en una tradición tecnológica basada en prácticas de enseñanza/aprendizaje cotidianas, con fuertes lazos sociales y culturales.

\section{Palabras clave}

Técnicas de manufactura alfarera Traceología

Petrografía Periodo Tardío Estilo Sanagasta/Angualasto Tambería de Guandacol 


\section{Manufacturing technique analysis of late Prehispanic pottery from Northwest of Argentina (13th - 17th century A.D.): A case-study of the Sanagasta/Angualasto style from the Tambería de Guandacol site (La Rioja Province)}



1. Bajo esta perspectiva, y a modo de ejemplo, un estilo tecnológico puede incluir un conjunto amplio de recipientes que poseen la misma tecnología de pastas composición y características-, y que sin embargo, algunos poseen decoración y otros no -estos últimos comúnmente conocidos y clasificados como cerámicas ordinarias o toscas en la literatura arqueológica del NOA-. En ese sentido, la única diferencia tecnológica dentro del universo cerámico que expresa el estilo es el tratamiento de superficie final o secundario. Estas variaciones internas son clasificadas por nosotros como componentes morfoestilísticos (Carosio, 2015; Carosio, Iniesta y Bárcena, 2011).

\begin{abstract}
This article presents the study and results of pottery production and manufacturing techniques at the Tambería de Guandacol site, Department of Felipe Varela, Province of La Rioja (Argentina). The ceramic assemblage is manufactured in the Sanagasta/ Angualasto style. This style is associated mainly with the Late prehispanic period in the Argentine Northwest (13th to 17th century A.D.). The assemblage is fragmentary. Nevertheless, employing ceramic petrography and trace analysis we address the operational chain and the organization of pottery production of the groups that inhabited the valley during this period. We also discuss the advances and limitations of this type of study on fragmentary records. The results show that there is uniform selection of primary and secondary techniques in the manufacture of ceramic vessels, while there is a degree of irregularity in the application method. In addition, there are technological similarities with coeval ceramics from the area. In turn, this allows us to propose the existence of a manufacturing process generated by a given community group, using different agents, and framed within a technological tradition founded on reiterated teaching/learning practices, linked strongly to social and cultural ties.
\end{abstract}

\section{Introducción}

El propósito de este trabajo es aportar al conocimiento sobre las técnicas de manufactura implementadas por los/as alfareros/as que habitaron el Valle de Guandacol (oeste de La Rioja) durante los siglos XIII-XVII d.C. Nuestro estudio se centra en el material cerámico del sitio Tambería (Bárcena, 2010; Callegari y Gonaldi, 2007-2008; De La Fuente, 1973), particularmente en su estilo predominante, Sanagasta/Angualasto (González y Pérez, 1972; Serrano, 1966). A partir de las evidencias de un registro netamente fragmentado, se intenta reconstruir las elecciones y gestos técnicos dentro del proceso de manufactura como un medio para dilucidar las tradiciones tecnológicas y sociales de ésta área del Noroeste Argentino.

Se considera a la cerámica como el resultado técnico de una "cadena operativa" (LeroiGourhan, 1964), la cual depende y deriva de una serie de elecciones, conscientes o no, durante cada una de las etapas de fabricación: obtención y preparación de materias primas, levantado y decoración cerámica, secado, cocción y tratamientos postcocción. Asimismo, se entiende como el desarrollo y alcance de pautas culturales materializadas por los ceramistas en un estilo tecnológico, un conjunto de "modos de hacer" en el que diferentes atributos - pastas, técnicas de levantado, formas, decoraciones y coccionesson regulares y recurrentes, definidos en un momento determinado y que expresan -aunque no necesariamente de manera directa-identidad social o un proceso mediante el cual ésta es formada y transformada. El estilo puede tener leves variaciones internas en cualquiera de sus atributos mencionados, aunque forman parte por igual de este patrón, inmerso en una misma pauta de racionalidad (Lechtman, 1977; Miller y Tilley, 1996) $)^{1}$.

Esta estructura operativa alfarera, dentro de un desarrollo de enseñanza/aprendizaje complejo, se halla dominada por elecciones rutinarias de elaboración, uso, intercambio 
y abandono de los recipientes en un espacio social, reiterada por los sujetos desde la infancia hasta la madurez. Ese carácter estructurado y habitual le otorga al proceso tecnológico cerámico un gran potencial como herramienta interpretativa de los modos de producción y su contexto en las comunidades del pasado y presente (Albero Santacreu 2014; Calvo Trías y García Rosselló 2011; Shanks y Tilley, 1987; van der Leew, 1993). Las decisiones técnicas dentro de esta secuencia pueden llegar a depender de múltiples factores, tales como la necesidad mecánica y/o funcional del recipiente a elaborar, la disponibilidad material que exhibe el ambiente para la fabricación, valores sociales e identitarios, influencias externas y ejercicios de dominio, entre otros. En cualquier caso, cuando las prácticas cerámicas son reproducidas y mantenidas en el tiempo, conforman una tradición y son inherentes a las dimensiones políticas y económicas que la contextualizan (Dobres y Hoffman, 1994; Gosselain, 1992; Lemonnier, 1992; Sillar, 2009).

Dentro de la cadena operativa cerámica, el proceso técnico del levantado del cuerpo del recipiente constituye uno de los más importantes, dado que es el conjunto de acciones que deforma la masa arcillosa -mediante presión aplicada- para lograr la forma final de la vasija antes de ser cocinada (Balfet, Fauvet-Berthelot y Monzón, 1992; Rye, 1981). Esta labor se realiza cuando la pasta se halla en estado plástico. Las particularidades de la arcilla en este momento posibilitan que durante todo el proceso -inclusive al final de la fase- pueda ir variándose la forma. Se trata de una etapa en la que la presencia del agua en la pasta aún es muy alta, manteniendo las características de plasticidad requeridas para su manipulación. Mediante un equilibrio entre el agua y la pasta durante el proceso también es preciso reducir progresivamente la humedad -a partir de diversas estrategias de secado- de la pieza que se va configurando, con el fin de que vaya obteniendo una mayor consistencia, lo que permitirá continuar trabajando sobre ella (García Roselló, 2011).

En líneas generales, existen dos tipos de información significativa que pueden desprenderse del análisis de las técnicas de manufactura durante el levantado: por un lado, los atributos físicos sobre el recipiente, y por otro, la secuencia de las acciones que intervienen en la labor alfarera. Los primeros se refieren a las marcas sobre la superficie, las formas particulares de fractura y a las protuberancias en las caras interna o externa del recipiente y características de inclusiones y cavidades en la pasta (Balfet et al., 1992; Rice, 1987; Rye, 1981). En cuanto a las acciones aplicadas durante la manufactura, hay que hacer hincapié en dos conceptos, según Rye (1981): la secuencia "esencial" y la de "secado". La primera se enlaza con los procedimientos que fueron aplicados en las primeras etapas de manufactura y comúnmente es aquella en la que se genera la forma base de la pieza. Por su parte, la secuencia de secado involucra la fase operativa en la que la vasija, ya con su forma base establecida, comienza a secarse o ponerse en estado "cuero". Cada una de estas elecciones y gestos técnicos pueden llegar a dejar lo que se conoce comúnmente como "traza", de acuerdo a la técnica y/o instrumento -en el caso que lo hubiere- que se utilice. Sin embargo, muchas veces es difícil y hasta imposible de determinar estos rasgos, y además, pueden ser opacados por marcas que se generan a partir de la utilización de otras técnicas en un momento posterior, como el acabado de la superficie y la decoración, el uso del recipiente y los procesos postdepositacionales que lo alteran.

Existen diferentes clasificaciones para el estudio de las secuencias del levantado cerámico. Uno de los más utilizados es el propuesto por Rye (1981), el cual distingue entre técnicas primarias y técnicas secundarias de manufactura. Las primarias son aquellas que aplican los/as alfareros/as para que la pasta sea modelada hasta lograr una forma base cerámica, la que de alguna manera reflejará la forma final de la vasija. Usualmente el recipiente se elabora por partes, sobre todo los de grandes dimensiones como las tinajas. Es común que se trabaje y complete el cuello y/o la base de la vasija 
hasta que se seque y adquiera el estado "cuero duro". La parte restante de la pieza, sobre todo el cuerpo, es terminada cuando el secado de la primera parte es suficientemente importante como para poder unir las dos secciones y cuando -en el caso de las basesse logra un soporte de fuerza para sostener al recipiente. Las técnicas secundarias de manufactura son las que se aplican normalmente en estado "cuero" o seco, es decir una vez que la forma de la vasija es definida y consumada y las proporciones relativas de las diferentes partes de una vasija son establecidas, logrando una homogeneización general del cuerpo final.

Los mejores acercamientos sobre estas técnicas provienen de los estudios etnográficos y experimentales, los cuales luego son comparados en investigaciones ceramológicas (Arnold, 1972; De La Fuente, 2011a; Druc, 2011; García Rosselló, 2011; entre otros). Aunque desde la arqueología muchas veces es difícil determinar y describir cómo fue esta compleja etapa de fabricación, los estudios de trazas o "traceológicos" permiten aproximarse a su determinación (García Rosselló, 2013; Martineau, 2002; Roux y Courty, 1998). Sin embargo, la mayor parte de estas labores se efectúan en muestras de recipientes completos. Para registros fragmentarios existen diferentes métodos analíticos que complementan los exámenes de trazas, tales como los estudios radiográficos, petrográficos, entre otros (Carr, 1993; De La Fuente, 2015; Livingstone Smith, 2007; López, Caramés y Acevedo, 2010; Middleton, 1997; Pérez, 2013; Rye, 1981; entre otros).

El análisis de técnicas de manufactura para este caso de estudio se basa en la implementación de un enfoque metodológico integrador, mediante exámenes convencionales macroscópicos (observación a ojo desnudo de trazas), submacroscópicos (examen de superficies y pastas cerámicas con lupa binocular) y microscópicos (análisis de láminas delgadas de pastas cerámica). El trabajo se inserta en el marco de los estudios ceramológicos locales y regionales sobre los modos de producción alfarera en el Noroeste Argentino durante los momentos prehispánicos (Cremonte, 2006; De La Fuente, 2011b; Feely, 2013; Pérez Pieroni, 2015; Puente, 2012; Zagorodny, Morosi, Iucci y Wynveldt, 2010; entre otros).

\section{Ubicación del área de estudio y antecedentes de investigaciones}

La Tambería de Guandacol se halla $2 \mathrm{~km}$ al sureste del pueblo homónimo, al oeste de La Rioja (Figura 1). El sitio se ubica a los $1050 \mathrm{~m}$ s.n.m., en un extenso barreal de unos 15 $\mathrm{km}^{2}$, entre la Precordillera y las Sierras de Maz y Morada (Sierras Pampeanas). El clima es árido y seco, con lluvias estivales y torrenciales -de las cuales se alimentan los ríos de deshielo principales, Guandacol y La Troya-, y vientos cálidos, lo que ha generado un ambiente semidesértico y vegetación xerófila (Capitanelli, 1992). En cuanto a los antecedentes de investigaciones, existen algunas primeras menciones del sitio en los trabajos arqueológicos e históricos regionales de De Aparicio (1936), Debenedetti (1917) y Canals Frau (1953). Estas labores, junto a otras del oeste de Catamarca y La Rioja y norte de San Juan (Bennet, Bleiler y Sommer, 1948; Boman, 1927-1932; Serrano, 1966; entre otros), describieron a los restos materiales -entre ellos la alfareríay los consideraron como parte de un complejo cultural que luego sería denominado "Sanagasta" o "Angualasto", asignado a los grupos Diaguitas mencionados en las fuentes españolas de los siglos XVI y XVII d.C. y temporalizado para el período Agroalfarero Tardío o de Desarrollos Regionales (ca. siglos X-XV d.C.) en el NOA (Gambier, 2000; González y Pérez, 1972; Tarragó, 2000).

Ahora bien, los estudios sistemáticos en la Tambería de Guandacol fueron realizados tiempo después, primeramente por De La Fuente (1973) y luego por Garrote y Callegari (1996) y Callegari y Gonaldi (2007-2008). Estos trabajos permitieron un conocimiento 


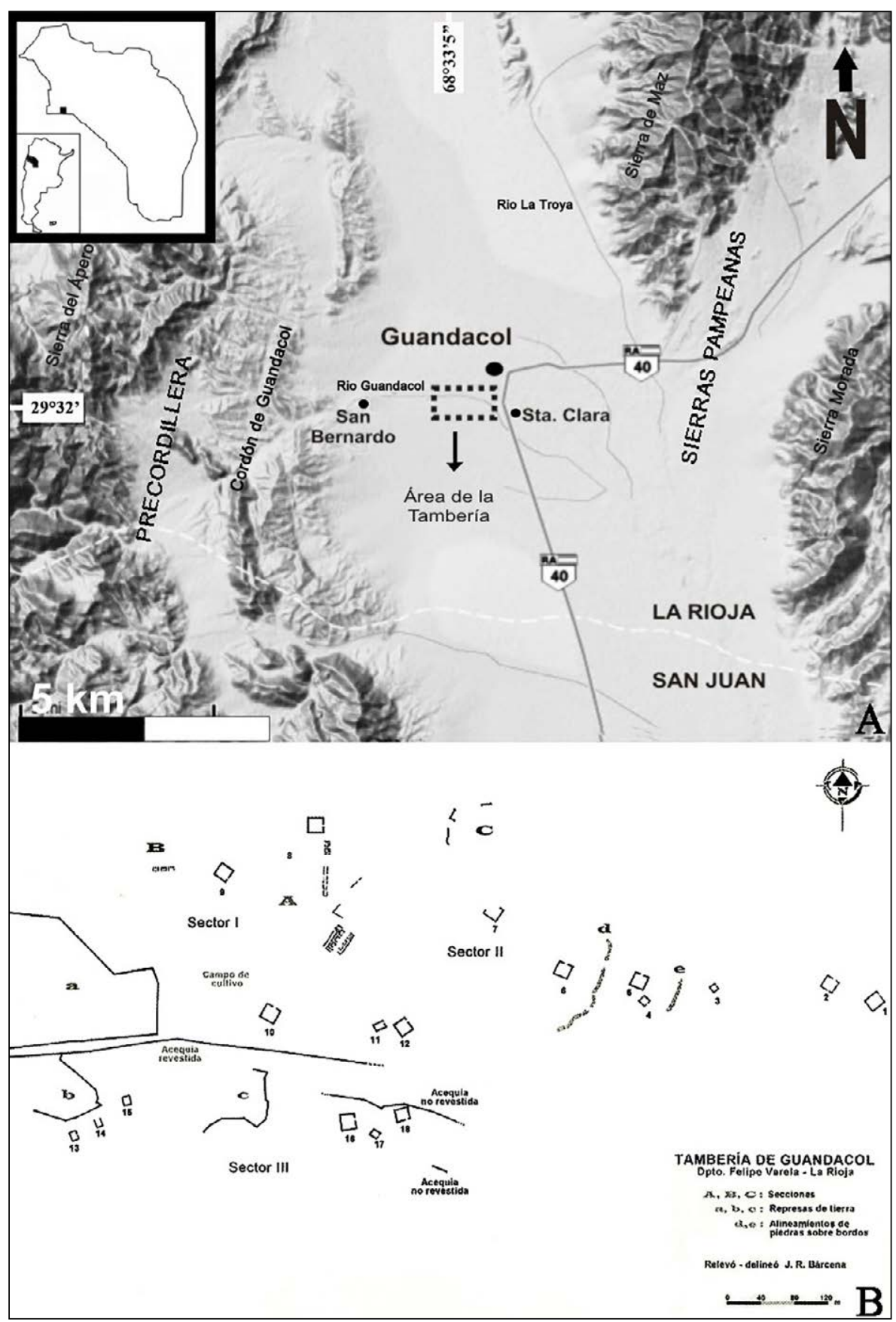

Figura 1. Ubicación del sitio Tambería, junto a las localidades de Guandacol, Santa Clara y San Bernardo, oeste de la Provincia de La Rioja.

sobre las estructuras arquitectónicas de barro del yacimiento, con impronta regional ${ }^{2}$, una descripción general del material cerámico - determinando los estilos Sanagasta/ Angualasto, Inca, Aguada y Diaguita Chileno Inca o Coquimbo- y las primeras dataciones radiocarbónicas, entre otros. Las investigaciones señalaron al sitio como un área de ocupación "Sanagasta" durante el Tardío y la etapa de dominio Inca -entre los siglos XIII y XVII d.C.

Desde el año 2007 y bajo la dirección de J. R. Bárcena, se amplió el registro de las numerosas estructuras de barro en el área y se reconoció una zona incaica intrasitio
2. La Tambería de Guandacol se inserta en una red de sitios arqueológicos del extremo sur valliserrano que ostentan cronologías relativamente contemporáneas y características arquitectónicas y otras evidencias materiales similares, tales como Angualasto, Pachimoco, Jáchal y otros del norte de la actual Provincia de San Juan (Gambier, 2000), Las Taperas, El Carmen, etc. del oeste de La Rioja (Spengler y Callegari, 2010), y Batungasta en el oeste de Catamarca (Sempé, 1977). 
con estructuras propias de la intervención estatal -cancha, collca, entre otras- recintos de almacenaje, abundantes canales de riego y campos de cultivo, instrumentos líticos -conanas, manos de moler- restos botánicos -algarroba, maíz, semillas diversas- y óseos -camélidos- Todas estas evidencias fueron asignadas a los periodos mencionados anteriormente y a comienzos de la etapa colonial -entre siglos XV y XVII d.C. Asimismo, se advirtió el alto grado de alteración natural y cultural en el yacimiento, lo que originó -y origina- el desmoronamiento y pérdida de estructuras arquitectónicas, el arrastre de material y un efecto de palimpsesto y solapamiento de restos que dificulta la buena interpretación del registro (Bárcena, 2010; Bárcena, Carosio e Iniesta, 2010). Recientemente se avanzó en estudios distribucionales, cronológicos y cerámicos en los alrededores del sitio, revelando la ausencia de estructuras arquitectónicas, la ocupación de espacios serranos y de bajada de río para los mismos periodos señalados para la Tambería, y la existencia de los mismos tipos de materiales (Iniesta y Bárcena, 2014).

En cuanto a las investigaciones cerámicas, nuestras tareas iniciales se preocuparon por la ordenación y caracterización general del registro, su ubicación espacial y su relación con el contexto arqueológico (Carosio, Iniesta y Bárcena, 2011). En ese sentido, se conformaron y discriminaron modalidades de manufactura o formas de hacer que fueron denominadas "componentes morfoestilísticos", clasificaciones alfareras basadas en grupos de piezas que presentan idénticos rasgos tecnológicos -características y composición de pastas, tratamientos superficiales, decoración y formas- y que forman parte de los distintos estilos cerámicos reconocidos para el sitio. Tal como señalan los estudios previos, se advirtió la predominancia de componentes pertenecientes al estilo Sanagasta/Angualasto en el sitio y la baja densidad de los otros estilos mencionados; la distribución relativamente homogénea de los conjuntos en el espacio de la Tambería; y el alto grado de fragmentación y alteración postdepositacional. En trabajos recientes se avanzó en la caracterización mineralógica y química de pastas, estableciendo una composición correspondiente con la geología local para las piezas del estilo mayoritario -y de otros como el Aguada e Inca Provincial. Se advirtió un tratamiento relativamente uniforme en el preparado de pastas Sanagasta/Angualasto, así como en otras fases de la cadena operativa, y se propuso la existencia de un modelo de producción alfarero propio, con pautas de aprendizaje de técnicas comunes transmitidas y mantenidas durante el Tardío que se extendió probablemente en tiempos de dominio Inca e inicios de la etapa colonial, nutrido asimismo de vínculos socioculturales extra regionales (Carosio, 2015).

De cualquier manera, hasta el momento son escasos los estudios específicos traceológicos sobre las técnicas de levantado implementadas por los/as alfareros/as en las cerámicas de la Tambería (Carosio, 2015). Si bien el estilo Sanagasta/Angualasto ha sido caracterizado en sus atributos morfológicos y decorativos en los trabajos pioneros ya mencionados y en otros modernos (Carosio, Aguilar y Bárcena, 2013; De La Fuente, 2011b; Méndez, 2008; Revuelta, Carosio y Aguilar, 2010-2012), solo recientemente se ha comenzado a indagar estrictamente en esta etapa de la cadena operativa alfarera, gracias a los aportes que provienen del análisis de trazas, exámenes radiográficos, observación microscópica y trabajos experimentales en piezas provenientes del oeste de Catamarca (De La Fuente, 2011a, 2011b, 2015; Feely, 2013).

\section{Materiales y métodos}

Para la identificación de las técnicas de manufactura es necesario el estudio complementario de tiestos individuales y de los grupos de fragmentos que conforman una misma pieza, tratando de definir el proceso de elaboración desde la base a la boca y determinando sistemas de fabricación concretos para poder instaurar modelos y patrones técnicos (García Rosselló, 2013). Es así que se estudiaron 7.892 fragmentos provenientes 


\begin{tabular}{|c|c|c|c|c|}
\hline Estilo tecnológico & Grupo & Componente morfoestilístico & UA & Frecuencia \% \\
\hline \multirow{5}{*}{ Sanagasta/Angualasto } & No Decorado & Alisado & 160 & 41 \\
& & Alisado Tosco & 99 & 25 \\
\cline { 2 - 5 } & \multirow{3}{*}{ Decorado } & Pulido y Pintado Pulido & 7 & 28 \\
& & Exciso & 6 & 2 \\
& & Pastillaje & 5 & 1 \\
\hline & \multicolumn{2}{|c|}{ Total } & 385 & 100 \\
\hline
\end{tabular}

Tabla 1. Conjunto de UA cerámicas. Componentes morfoestilísticos del Estilo Sanagasta/Angualasto de Guandacol.

de recolecciones superficiales sistemáticas realizadas en la Tambería (Carosio, 2015; Carosio et al., 2011). Poseen tamaños diversos, con un promedio de $7 \mathrm{~cm}$ de largo por $8 \mathrm{~cm}$ de ancho, aunque el rango se ubica con medidas entre los $1,5 \mathrm{~cm}$ y los $15 \mathrm{~cm}$, y el espesor promedio es de $1,2 \mathrm{~cm}$. Conforman distintas partes de recipientes, aunque la mayoría pertenecen a cuerpos y bordes. Los tiestos fueron agrupados de acuerdo a sus rasgos tecnológicos generales -características de pastas, superficies, espesores- $\mathrm{y}$ mediante remontaje en 385 Unidades de Análisis (UA) o número de vasijas (Orton, Tyers y Vince, 1997). Estas pertenecen exclusivamente a los componentes morfoestilísticos del estilo tecnológico Sanagasta/Angualasto. Del total, solo 126 UA poseen decoración (Tabla 1). A pesar del alto estado de fragmentación se pudo diferenciar las formas en dos grandes grupos: vasijas de perfil no restringido -formas abiertas-, entre los que se hallan cuencos o pucos y platos, y por otro lado recipientes de perfil restringido -formas cerradas-, como son las ollas y tinajas (Balfet et al., 1992). Luego se discriminaron variaciones morfológicas dentro de las dos formas más abundantes -cuencos y ollas-, estableciendo así, entre los primeros, cuencos globulares y subglobulares pequeños y cuencos subglobulares grandes; y dentro de las segundas, ollas globulares de perfil invertido y ollas globulares de perfil evertido. También se incluyeron en el estudio piezas con formas indeterminadas (Tabla 2, Figura 2).

Para el análisis de las técnicas de manufactura se siguieron los lineamientos propuestos por García Rosselló (2013) y Rye (1981), distinguiendo primeramente entre técnicas primarias y secundarias de manufactura. Dentro de las últimas se estableció una diferencia entre: a) tratamientos de superficie primarios, que son aquellas ejecuciones técnicas realizadas cuando la arcilla está en estado plástico y cuero y que permiten uniformizar la superficie dándole cierta regularidad; b) tratamientos de superficie secundarios, los cuales se destinan a dar el aspecto final de los recipientes y que coinciden normalmente con la decoración; y c) la fabricación y aplicación de elementos de prensión, es decir, aquellas técnicas utilizadas para completar mediante la adición de pasta para resaltar aspectos decorativos, otorgar facilidades de manipulación y dar forma final al recipiente, las cuales pueden ocurrir en diferentes etapas operativas pero comúnmente cuando la pasta está en estado plástico y cuero. Se recurrió a la totalidad de las UA conformadas; sin embargo, para la identificación de las técnicas primarias solo se pudo contar con 101 UA $-26,23 \%$ de total-, ya que en el resto fueron muy difíciles de identificar, sea porque los tiestos de las UA no mostraron evidencias de las técnicas o porque su tamaño dificultó una clara apreciación. El reconocimiento de procedimientos se basó en un estudio de trazas en los tiestos a partir de la observación macroscópica y submacroscópica -utilizando lupa binocular Olympus Zoom Stereo Microscope SZ/Tr-. Se identificaron los patrones de fractura y la presencia y el tipo de marcas en superficies, incluyendo tanto las originadas por la acción directa del/a alfarero/a -marcas de herramientas y digitales, variaciones de espesor, etc.- como 


\begin{tabular}{|l|c|c|c|c|c|c|c|}
\hline Formas & UA & $\begin{array}{c}\text { Espesor } \\
\text { promedio } \\
\text { cuerpo }\end{array}$ & $\begin{array}{c}\text { Espesor } \\
\text { promedio } \\
\text { base }\end{array}$ & $\begin{array}{c}\text { Espesor } \\
\text { promedio } \\
\text { borde }\end{array}$ & $\begin{array}{c}\text { Diámetro } \\
\text { promedio } \\
\text { boca }\end{array}$ & $\begin{array}{c}\text { Diámetro } \\
\text { promedio } \\
\text { base }\end{array}$ & $\begin{array}{c}\text { Diámetro } \\
\text { promedio } \\
\text { cuerpo }\end{array}$ \\
\hline Ollas globulares de perfil invertido & 21 & 1,2 & 2 & 1 & 26 & 11 & - \\
Ollas globulares de perfil evertido & 68 & 1,4 & 2 & 1,1 & 29 & 11 & 35 \\
Cuencos globulares y subglobulares pequeños & 73 & 0,9 & 1,8 & 0,8 & 16 & 5 & 18 \\
Cuencos globulares y subglobulares grandes & 107 & 1,1 & 2 & 1 & 23 & 8 & 30 \\
Tinajas & 17 & 1,7 & 2,3 & 1,2 & 29 & 12 & - \\
Platos & 10 & 0,5 & 1 & 0,5 & 20 & - & - \\
Indeterminadas & 89 & 1,1 & - & - & - & - & - \\
\hline Total & 385 & 0,9 & 2 & 0,8 & 23 & 9 & 28 \\
\hline
\end{tabular}

Tabla 2. Características métricas principales de las formas.

A

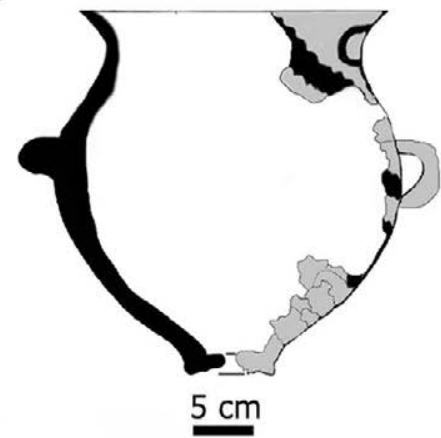

D

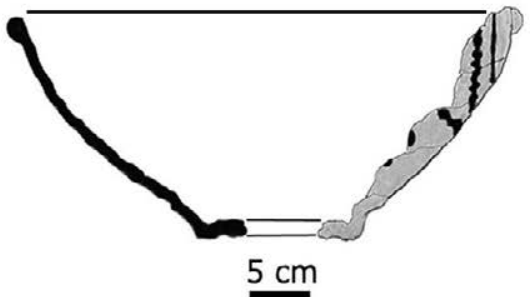

B

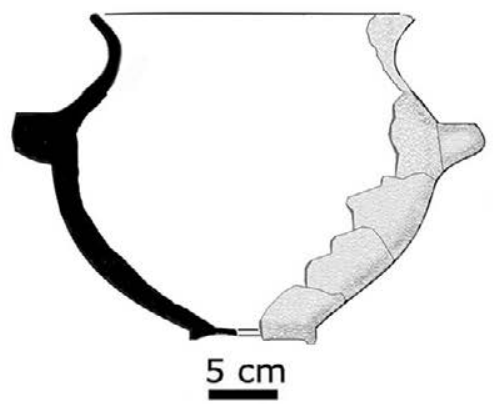

$\mathbf{E}$

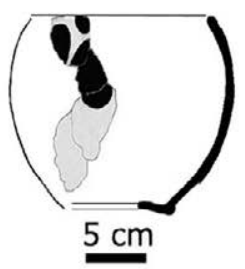

C



$\mathbf{F}$

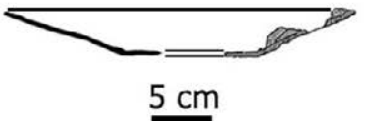

Figura 2. Morfologías reconocidas en el registro cerámico de la Tambería: A) tinajas; B) ollas globulares de perfil evertido; C) ollas globulares de perfil invertido; $D$ ) cuencos globulares y subglobulares grandes; $E$ ) cuencos globulares y subglobulares pequeños; $F$ ) platos.

aquellas no producidas por los ceramistas, sino que son evidencias indirectas -fracturas, surcos, entre otras- (Balfet et al., 1992; De La Fuente, 2011a; García Rosselló, 2013; Gibbs, 2008; López, 2000-2002; Roux y Courty, 1998). Se consideraron aquellas marcas que no fueron borradas por los pasos subsiguientes de la cadena operativa. Si bien en el material fragmentario muchas de estas huellas, sus direcciones o distribución son difíciles de observar, en las piezas más reconstruidas y cuasi completas -con todas las partes correspondientes a la vasija- se pudo abordar con mayor precisión.

Por otro lado, a partir de la observación exploratoria con microscopio petrográfico Olympus BX51 de 84 láminas delgadas de tiestos cerámicos correspondientes a todas las formas se registró la orientación de inclusiones, cavidades y grietas, así como sus formas. Se utilizaron cortes realizados perpendicularmente a la vasija $(n=25)$ y de 
forma paralela $(n=59)$ y se siguieron los parámetros de observación de diferentes estudios (De La Fuente, 2015; González de Bonaveri, Frére y Solá, 2000; Livingstone Smith, 2007; Rye, 1981; Woods, 1985). La orientación de los componentes de la pasta y cavidades, así como sus formas, es un rasgo que se vincula con el modo en que se ejerce presión y manipulación sobre la pasta y por ende con las técnicas de manufactura (Albero Santacreu, 2014). Toda la información fue comparada con los estudios de técnicas de manufactura de recipientes Sanagasta/Angualasto ya mencionados (Boman, 1927-1932; De La Fuente, 2011b, 2015; Feely, 2013; Varela, 2005).

\section{Resultados}

\section{Técnicas de manufactura primaria}

En líneas generales se observa una homogeneidad en la aplicación de técnicas de manufactura primaria para la mayoría de las formas documentadas (Tabla 3). La técnica predominante y mejor reconocida para las diferentes formas del registro es la de rodeteado $(n=86 \mathrm{UA})$, mediante la preparación y superposición de rodetes de pasta de forma horizontal ensamblados por compresión, estiramiento y arrastrado. Estos rollos poseen diversos espesores, los de mayor tamaño corresponden a tinajas y ollas de perfil evertido -entre 3 y $4 \mathrm{~cm}$ - y los menores a cuencos -2 y $3,5 \mathrm{~cm}$-, identificados esencialmente en bordes y cuerpos de recipientes.

Los rodetes se pueden distinguir a partir de diferentes indicadores, algunos más precisos que otros. En muchos casos se advierten a escala macroscópica y submacroscópica -en corte fresco de tiestos- pero cuando esto no es posible, los rastros son los siguientes: a) orientación horizontal y parcial de los antiplásticos en las caras superficiales -vista normal a la pared de la pieza-, y orientación circular de partículas en bases en cara interna -vista normal desde arriba- (esto fue observado solo en $16 \mathrm{UA}$, dado que la mayoría se hallan incompletas), b) grietas aplanadas en la fractura perpendicular de la vasija, c) diferencias de espesor en el perfil horizontal de la pared, tanto en el interior como el exterior de la pieza -entre la unión de los rodetes-, d) quiebres selectivos paralelos a la pared de recipiente en la zona de unión entre rodetes, e) marcas de la unión defectuosa, principalmente en la superficie interna, $\mathrm{y} f$ ) ondulaciones y surcos horizontales en distintos sectores del cuerpo de las vasijas -aunque en ocasiones esto no fue posible de determinar por el alisamiento posterior de las caras superficiales- (Figuras 3A, B, C, D, E, F).

El arrastrado de rodetes en la mayoría de los recipientes se distingue por la presencia de arcilla o rebabas que sobresalen en las caras internas de los recipientes -esencialmente en la unión entre bases y cuerpos, y en ocasiones entre cuerpo y bordes de las ollas y tinajas- (Figura 3G). En excepcionales casos en los que los tiestos poseen gran tamaño y que se lograron remontar, se reconoce en las superficies internas deformaciones que podrían indicar el área en la que se superpone el rodete en espiral.

Los cuellos y bordes de vasijas en general suelen mantener el perfil continuo con el de los cuerpos, sin trazas que reflejen un cambio abrupto o punto de inflexión. Sin embargo, en la sección superior de borde/labio de algunas ollas y algunos cuencos $(n=49 \mathrm{UA})$ se han podido distinguir hendiduras en formas onduladas y discontinuas en la parte inferior que permiten inferir un engrosado del labio a partir del añadido de rollo de pasta, luego pellizcado (Figura 3H, I, J) (García Rosselló, 2013). Este tipo de añadido también se advirtió en numerosos tiestos de bordes y cuerpos ( $\mathrm{n}=32 \mathrm{UA}$ ), que muestran rebabas y un grosor mayor de la pared en la zona de unión entre ambas partes -cuello-, en la cara interna de las piezas. Esto indicaría que el cuello y borde se modelaron sobre el cuerpo de la vasija mediante superposición de rollos en una etapa en la que el cuerpo inferior se halla con cierta dureza producto del secado (Rye, 1981). 


\begin{tabular}{|c|c|c|c|c|c|c|c|c|c|}
\hline & & & \multicolumn{7}{|c|}{ Formas } \\
\hline & & & $\begin{array}{c}\text { Ollas } \\
\text { globulares } \\
\text { de perfil } \\
\text { invertido }\end{array}$ & $\begin{array}{c}\text { Ollas } \\
\text { globulares } \\
\text { de perfil } \\
\text { evertido }\end{array}$ & $\begin{array}{l}\text { Cuencos } \\
\text { globulares } \\
\text { y subglo- } \\
\text { bulares } \\
\text { pequeños }\end{array}$ & $\begin{array}{c}\text { Cuencos } \\
\text { globulares y } \\
\text { subglobulares } \\
\text { grandes }\end{array}$ & Tinajas & $\begin{array}{l}\text { Pla- } \\
\text { tos }\end{array}$ & $\begin{array}{l}\text { Indeter- } \\
\text { minadas }\end{array}$ \\
\hline \multirow{5}{*}{$\begin{array}{l}\text { Técnicas } \\
\text { primarias de } \\
\text { manufactura }\end{array}$} & \multicolumn{2}{|l|}{ Rodeteado } & $x$ & $x$ & $x$ & $x$ & $x$ & & $x$ \\
\hline & \multicolumn{2}{|l|}{ Arrastrado } & $x$ & $x$ & -- & $x$ & $x$ & -- & -- \\
\hline & \multicolumn{2}{|c|}{ Estiramiento de masa } & $x$ & $x$ & $x$ & $x$ & -- & $x$ & $x$ \\
\hline & \multicolumn{2}{|l|}{ Pellizcado } & -- & $x$ & -- & -- & -- & $x$ & -- \\
\hline & \multicolumn{2}{|c|}{ Ahuecamiento de masa } & -- & -- & $x$ & -- & -- & $x$ & -- \\
\hline \multirow{11}{*}{$\begin{array}{l}\text { Técnicas } \\
\text { secundarias } \\
\text { de } \\
\text { manufactura }\end{array}$} & \multirow{4}{*}{$\begin{array}{l}\text { Técnicas de } \\
\text { tratamiento } \\
\text { de } \\
\text { superficie } \\
\text { primario }\end{array}$} & Alisado & $x$ & $x$ & $x$ & $x$ & -- & $x$ & $X$ \\
\hline & & $\begin{array}{l}\text { Alisado } \\
\text { tosco }\end{array}$ & -- & $x$ & -- & -- & $x$ & -- & $x$ \\
\hline & & $\begin{array}{l}\text { Alisado/ } \\
\text { cepillado }\end{array}$ & $x$ & $x$ & $x$ & $x$ & $x$ & $x$ & -- \\
\hline & & Raspado & -- & $x$ & -- & $x$ & $x$ & -- & -- \\
\hline & \multirow{4}{*}{$\begin{array}{l}\text { Técnicas de } \\
\text { tratamiento } \\
\text { de } \\
\text { superficie } \\
\text { secundario }\end{array}$} & Pintado & $x$ & $x$ & $x$ & $x$ & $x$ & $x$ & -- \\
\hline & & Baño & -- & $x$ & $x$ & -- & $x$ & $x$ & -- \\
\hline & & Pulido & -- & -- & $x$ & $x$ & -- & $x$ & -- \\
\hline & & Exciso & -- & -- & $x$ & -- & -- & -- & -- \\
\hline & \multirow{3}{*}{$\begin{array}{l}\text { Aplicación } \\
\text { de } \\
\text { elementos } \\
\text { de prensión }\end{array}$} & $\begin{array}{l}\text { Asa } \\
\text { remachada }\end{array}$ & -- & $x$ & -- & -- & $x$ & -- & -- \\
\hline & & $\begin{array}{l}\text { Asa } \\
\text { adherida }\end{array}$ & -- & -- & $x$ & $x$ & -- & -- & -- \\
\hline & & Pastillaje & -- & -- & $x$ & -- & -- & -- & -- \\
\hline
\end{tabular}

Tabla 3. Cuadro comparativo de técnicas primarias y secundarias de manufactura para las diferentes formas presentes en el registro.

Para la confección de bases de recipientes -la mayoría de tipo menisco/convexas y bicóncavas, aunque existen algunas planas- también se distingue el uso del rodeteado, mediante la aplicación de rollizos acoplados por aplanado, extendido y arrastrado. Esto se evidencia a partir de la orientación circular y concéntrica de partículas en la pared interna de la vasija, así como también en grietas en la fractura perpendicular al recipiente de formas aplanadas y grietas internas paralelas dentro de la base que se observan en el corte fresco de la pared (Figura 4A, B y C). En algunos casos, fundamentalmente en bases de tinajas y ollas, también se reconocen líneas rectas y/o curvas atravesando la base de lado a lado por el centro, y que luego se dirigen hacia la zona de unión con el cuerpo del recipiente, lo que sugiere la utilización de alguna herramienta para el armado y estiramiento de masa una vez aplanados los rodetes (Livingstone Smith, 2007). Asimismo, también se registran fracturas laminares indicativas de reforzamiento de bases con planchas o placas de masa arcillosa $(n=15 \mathrm{UA})$, así como grietas y fracturas surgidas en el punto del engrosamiento exterior a partir de la aplicación de masa arcillosa y círculos de pasta para su ensanchado, ensamblado por arrastrado (Figura 4D y E). Sin embargo, muchas bases también exhiben una uniformidad de bloque de masa sin diferenciación en su corte transversal, una aleatoriedad en la distribución y ordenación de partículas antiplásticas de la pasta, ondulaciones verticales, y la impresión de huellas digitales $(\mathrm{n}=19 \mathrm{UA})$-a veces borradas por el alisamiento(Figura 4F y H). Esto sugeriría un modelado inicial a partir de una bola de arcilla ahuecada y posterior estiramiento inicial hacia las paredes sobre las que se comenzarían a superponer los rodetes (García Rosselló, 2013). 

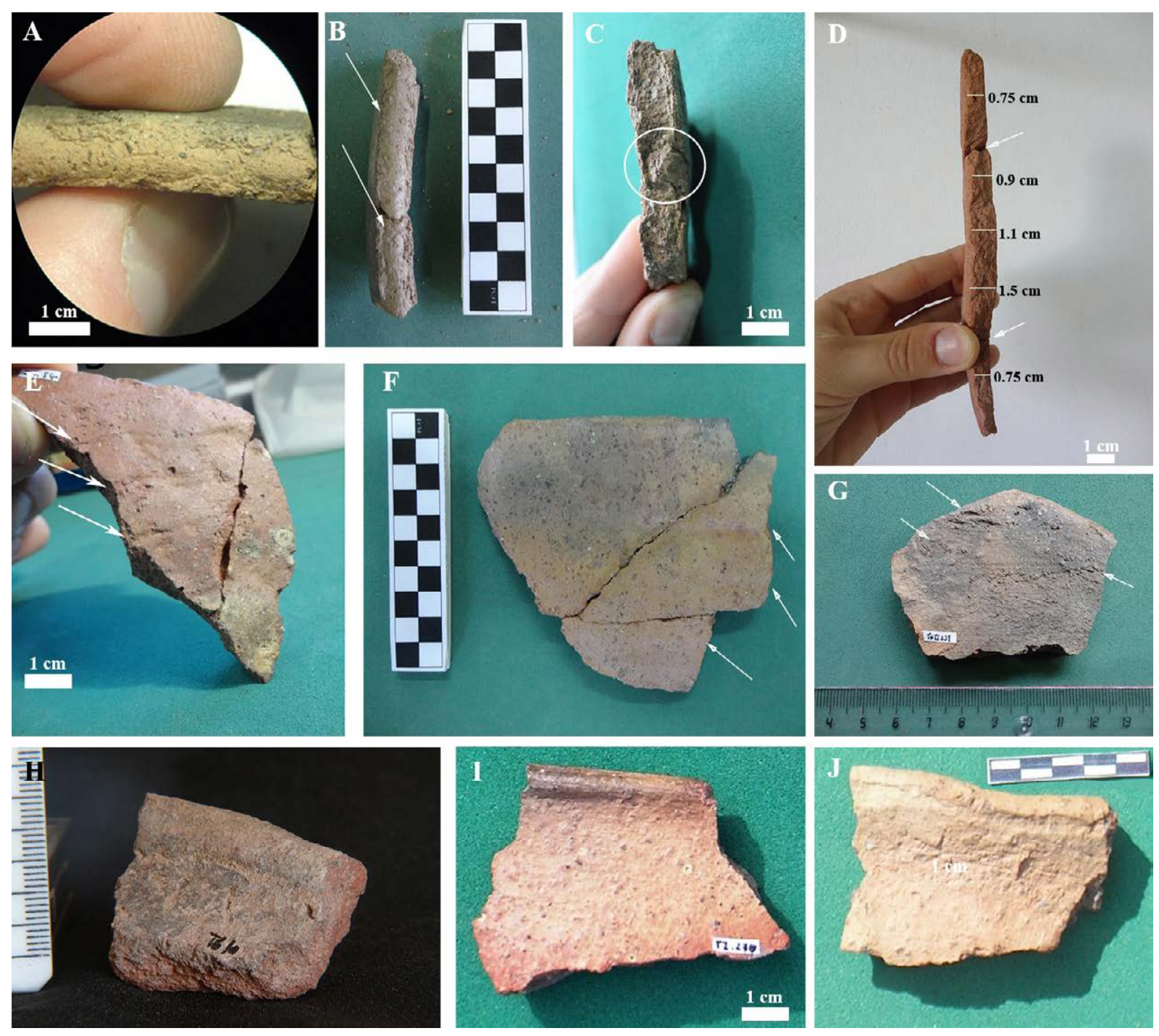

Figura 3. Fotografías de evidencias de trazas vinculadas a las técnicas primarias de manufactura en bordes y cuerpos. A y $B$ ) rodete superpuesto en fragmento de cuerpo de cuenco subglobular (A - lupa binocular. B-las flechas señalan rodete); $C$ ) fragmento de cuerpo de olla globular de perfil evertido en el que sobresale estructura de rodete (círculo) en corte transversal de la pared (natural); D) corte perpendicular de cuenco subglobular en la que se señalan las fracturas entre rodillos superpuestos (flechas) y las variaciones de espesor de la pared producto del arrastrado y presionado de rodetes; E y F) cuencos subglobulares en los que se señala (flechas) los surcos de superposición de rodillos en la superficie externas; $G$ ) fragmento de borde de cuenco subglobular en el que se evidencia (flechas) los rastros de rebabas producto del arrastrado de rodetes; $H$, I y J) fragmentos de borde de olla globular $(H)$ y cuencos subglobulares (I, J), en los que se advierte el engrosado de labio.

Otro aspecto significativo detectado en bases más completas es la diferencia de espesor entre las bases y el cuerpo superior del recipiente, principalmente en las zonas de unión entre ambas partes. Este rasgo se debe probablemente a un proceso de secado diferencial entre una sección y la otra, y la posterior unión de las partes. Algo llamativo en el conjunto global de bases, además de la forma, es la gran similitud de tamaños con un promedio diámetro de $11 \mathrm{~cm}$ para ollas, $12 \mathrm{~cm}$ para tinajas y $8 \mathrm{~cm}$ para cuencos, $\mathrm{y}$ espesores que no superan los $2 \mathrm{~cm}$ (Carosio, 2015). Esto permite sugerir la utilización de algún tipo soporte o molde común en dimensiones (Courty y Roux, 1995). En ningún caso se ha observado la presencia de marcas de otro tipo de soportes como pueden ser los cestos.

Excepcionalmente se registraron 9 UA con bases tipo pedestal para tinajas, muchas de las cuales ostentan fracturas internas que permiten distinguir dos secciones en el 

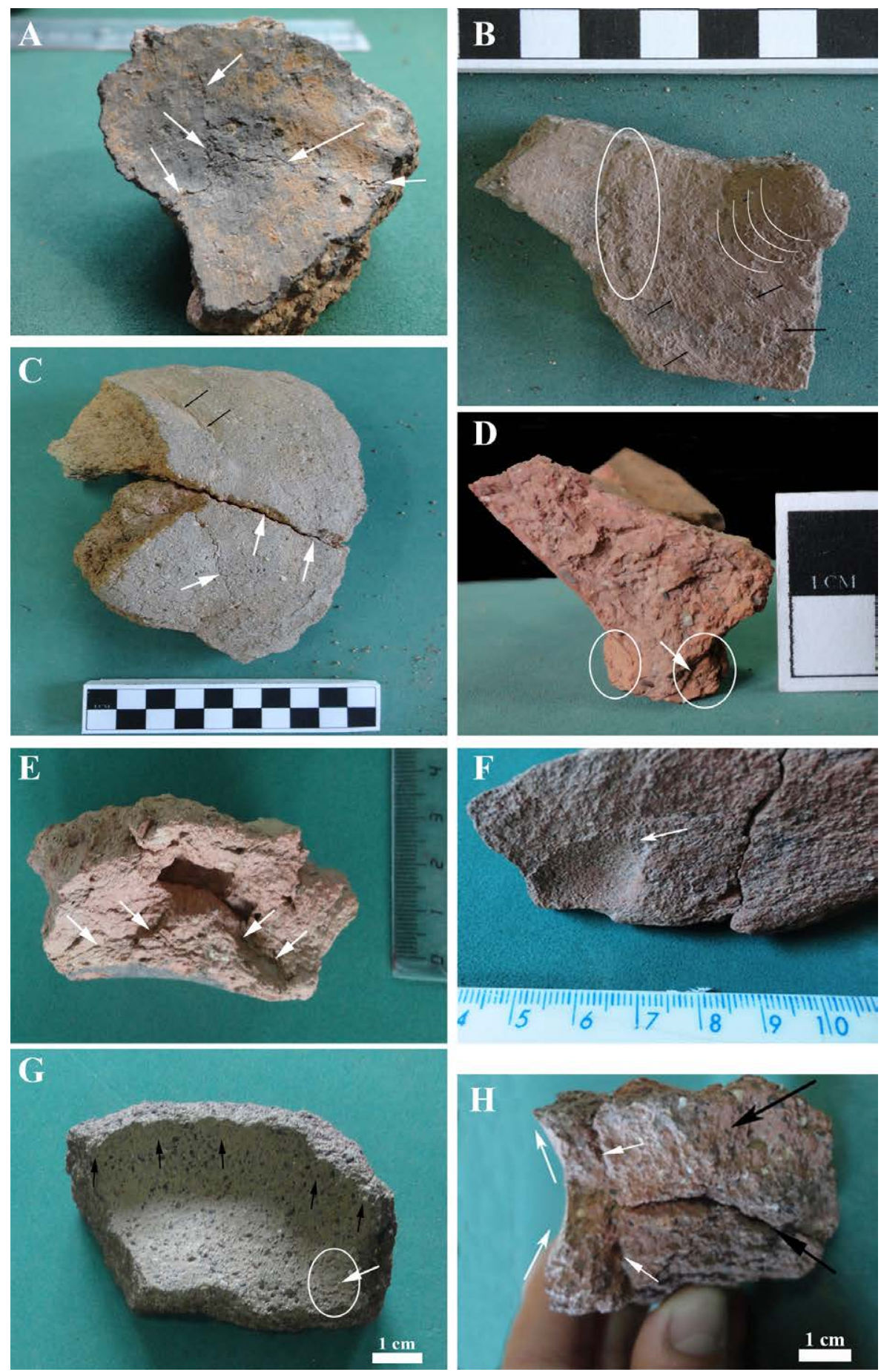

Figura 4. Fotografias de evidencias de trazas vinculadas a las técnicas primarias de manufactura. A) fragmento de base de tinaja con fracturas (señaladas con flecha) que indican la utilización de la técnica de rodete superpuesto; $B$ ) base de cuenco subglobular en la que se evidencia la orientación de antiplásticos y surcos (líneas oblicuas) que indican la confección de base mediante técnica de rodeteado, el raspado de superficie para emparejar y arrastrar la pasta de rodetes (flechas negras), y el añadido de arcilla para darle fuerza a la unión de la base y el cuerpo superior (óvalo); C) fragmento de base de tinaja con fracturas que indican la utilización de la técnica de rodetes superpuestos (señaladas con flechas blancas) y la unión entre la base y el cuerpo superior (señaladas con flechas negras); D) fragmento de base de cuenco subglobular con fractura (flecha) que indican la separación entre la masa arcillosa primaria y el agregado de pasta para reforzar la base (círculo); E) fragmento de base de tinaja que presenta fractura laminar (flechas) que indican el añadido de placa arcillosa para reforzar; $F$ y $G$ ) bases de cuencos en el que se observa huellas digitales (flechas) producto de la técnica de pellizcado, y la orientación vertical de antiplásticos (G) que indican el estiramiento de masa (flechas negras); $H$ ) base tipo pedestal de tinaja en la que se observa el cilindro de masa arcillosa primario fracturado (flechas negras) y la fractura de que indica su separación con el añadido de pasta para su refuerzo y estiramiento (flechas blancas). 
pedestal: por un lado un cilindro de masa extendido, de $5 \mathrm{~cm}$ de espesor y $6 \mathrm{~cm}$ y 5 $\mathrm{cm}$ de largo y ancho, respectivamente; asimismo, una extensión de masa arcillosa que bordea el cilindro en toda su extensión (Figura 4H). Esto sugiere la conformación de estas bases en más de una fase, primeramente mediante modelado de un soporte sólido del cuerpo cerámico -esencialmente ollas y tinajas de gran porte y peso- y luego, a raíz de reforzar la resistencia del pedestal para el sostenimiento de la vasija, agregando y presionando pasta, recubriéndolo y dándole volumen para agrandar su tamaño acorde al sostenimiento del recipiente que se está confeccionando. Finalmente, en casi todas las bases de tinajas y ollas de perfil evertido se advierte el añadido de arcilla para completar y emparejar los fondos y para unir con la sección del cuerpo superior.

En definitiva, para tinajas y ollas de gran tamaño las evidencias permiten suponer la elaboración en diferentes etapas: bases, cuerpos y cuello/borde de manera aisladas. Los cuerpos se colocarían por encima de la base una vez que éstas se hallaran prácticamente secas, al igual que el cuello/borde una vez que el cuerpo se encuentre en ese estado. Una vez levantado parte del cuerpo por encima de la base, el área de unión entre estas se reforzó con un presionado interior y exterior -tal como se advierte con las hendiduras enfrentadas y discontinuas en las paredes interior y exterior a la altura de la unión de ambas secciones-, así como mediante el adicionado de arcilla para reforzar áreas incompletas, desparejas y con debilidad. Si bien en cuencos globulares y subglobulares grandes no se reconoce el añadido de pasta en el área de unión cuerpo/base, no sería extraño que también hubiera existido un tratamiento similar a las piezas anteriores, dado el gran tamaño que poseen. Sin embargo, esas trazas quedarían prácticamente desleídas al poder aplicar un tratamiento de alisamiento interno con mayor facilidad que ollas y tinajas en etapas posteriores de la manufactura.

Otra de las técnicas primarias distinguidas exclusivamente para algunos cuencos globulares y subglobulares pequeños, platos y piezas indeterminadas, es el modelado por ahuecamiento de masa, estiramiento de paredes y pellizco, extendiendo las paredes del recipiente hacia los costados y cuerpo superior $(n=15$ UA). Esto se diferenció a partir de: a) un ordenamiento preferentemente vertical y aleatorio de inclusiones y rebabas en las paredes de los recipientes -vista normal y paralela a la vasija-; b) impresiones digitales por presión y huellas de arrastrado -realizado probablemente mediante alguna herramienta- en dirección vertical u oblicua; $y \mathrm{c}$ ) leves variaciones de espesor en el perfil perpendicular al recipiente (Figura 5A, B, C, D, E, F) (Martineau, 2002).

En cuanto al estudio de láminas delgadas, los resultados se mostraron heterogéneos de acuerdo a la orientación paralela o perpendicular del corte en el recipiente. En láminas delgadas paralelas de ollas, tinajas y la mayor parte de los cuencos y piezas indeterminadas, las cavidades se advierten elongadas -aunque también las hay esféricas-, con orientación fluidal o paralela y subparalela. Esa alineación también se reconoce para los antiplásticos. En cortes perpendiculares sobre los mismos tipos de recipientes se identifica una orientación relativamente aleatoria y subparalela de los antiplásticos, y escasamente una orientación subparalela de cavidades elongadas y partículas, además de grietas que atraviesan de lado a lado la matriz. Este panorama, a pesar de ser estimativo, podría reflejar del uso de la técnica de rodeteado (De La Fuente, 2015; González de Bonaveri et al., 2000). Sin embargo en láminas delgadas paralelas al recipiente -fundamentalmente en cuencos y platos-, la disposición aleatoria y subparalela de partículas antiplásticas y de cavidades, así como la presencia de poros redondeados, podría implicar un estiramiento de las paredes y presiones discontinuas originadas por la aplicación de la técnica de pellizcado (Courty y Roux, 1995; Livingstone-Smith, 2007) (Tabla 4) (Figura 6A, B, C, D, E, F). 



Figura 5. Fotografías de evidencias de trazas vinculadas a las técnicas primarias de manufactura. $A, B, C)$ cuerpos de plato $(C)$ y cuenco $(A$ y $B$ ) en el que se registra trazas (flechas) vinculadas con el arrastrado diagonal y vertical de pasta mediante herramientas; $D$ ) borde de cuenco en el que se observan rebabas producto del arrastrado y estiramiento de masa vertical y oblicuo; E) borde de plato en el que se evidencia las huellas de presión producto del uso de la técnica de pellizcado (círculo); F) borde de plato en el que se registra trazas vinculadas con el arrastrado vertical de pasta mediante herramientas (flechas) y las huellas de presión producto del pellizcado (óvalo).

\section{Técnicas secundarias de manufactura}

\section{Técnicas de tratamientos de superficie primario}

Las técnicas de tratamiento primario se advirtieron uniformes en el registro general, aunque existen ciertas particularidades (Tabla 3). Una de las técnicas más abundantes es el alisado (116 UA), el cual se destaca por la ausencia de rugosidades y asperezas palpables, además de una orientación parcial de partículas antiplásticas en la pasta (Figura 7A). Se reconoce de forma generalmente uniforme en todo el recipiente, aunque con mayor regularidad en cuecos, platos y ollas globulares de perfil invertido; mientras que en tinajas y ollas globulares de perfil evertido se exhibe más irregular. Las caras más trabajadas en cuencos y platos son ambas, mientas que en tinajas y ollas la superficie externa es la más alisada. El procedimiento parece haber sido ejecutado preferentemente con la mano, con una presión y frotamiento recurrente en las paredes de las piezas, mientras estas se hallaban todavía con cierta humedad (Rye, 1981). Otra técnica similar a la anterior es un tratamiento que clasificamos como alisado tosco (80 UA), reconocido fundamentalmente en tinajas y ollas subglobulares grandes, pero también en las restantes formas. Se diferencia del alisado en el hecho de que se evidencia una rugosidad mayor en las paredes de recipientes, con partículas de inclusiones de pasta con ordenación aleatoria y de masa arcillosa palpables que otorgan protuberancias en toda la pieza, en ambas caras superficiales (Figura 7B). Ello denota un escaso tratamiento de emparejamiento de la 


\begin{tabular}{|c|c|c|c|c|}
\hline $\begin{array}{l}\text { Tipo de lámina } \\
\text { delgada }\end{array}$ & $\begin{array}{l}\text { Parte de } \\
\text { vasija }\end{array}$ & $\begin{array}{l}\text { Orientación de } \\
\text { antiplásticos }\end{array}$ & $\begin{array}{l}\text { Orientación de } \\
\text { cavidades }\end{array}$ & Microfracturas \\
\hline \multirow{3}{*}{$\begin{array}{l}\text { Paralelo a } \\
\text { recipiente }\end{array}$} & Borde & Subparalela & $\begin{array}{c}\text { Paralela, subparalela } \\
\text { y aleatoria }\end{array}$ & No observable \\
\hline & Cuerpo & $\begin{array}{c}\text { Paralela y } \\
\text { subparalela }\end{array}$ & $\begin{array}{c}\text { Paralela, subparalela } \\
\text { y aleatoria }\end{array}$ & No observable \\
\hline & Base & Subparalela & Subparalela & No observable \\
\hline \multirow{3}{*}{$\begin{array}{l}\text { Perpendicular } \\
\text { a recipiente }\end{array}$} & Borde & $\begin{array}{l}\text { Moderamente } \\
\text { aleatoria }\end{array}$ & Aleatoria & Observable \\
\hline & Cuerpo & $\begin{array}{l}\text { Subparalela y } \\
\text { aleatoria }\end{array}$ & $\begin{array}{c}\text { Subparalela y } \\
\text { aleatoria }\end{array}$ & Observable \\
\hline & Base & $\begin{array}{l}\text { Moderamente } \\
\text { aleatoria }\end{array}$ & $\begin{array}{l}\text { Moderamente } \\
\text { aleatoria }\end{array}$ & No observable \\
\hline
\end{tabular}

Tabla 4. Características del ordenamiento de antiplásticos y cavidades en láminas delgadas paralelas y perpendiculares $(N=84)$.

pared durante el acabado primario de la vasija -todavía con humedad-, además de una presión sin mucha intensidad y recurrencia (Gibbs, 2008).

Otro procedimiento técnico abundante en el registro es el alisado/cepillado (147 UA), observado fundamentalmente en cuencos. Este tratamiento deja huellas sobre la superficie cerámica en forma de líneas -alrededor de 6 o 9- paralelas de forma suave, débil, a veces desleídas y sin remover mucha pasta. Siguen un patrón generalmente multidireccional a la pieza -paralela y oblicua- y de forma irregular, es decir, sin una aplicación al total de la cara superficial (Figura 7C). El tratamiento genera que las partículas de la pasta cerámica presenten una orientación parcial, aunque en las bases de manera aleatoria. Si bien se registra en paredes internas y externas, solo que en cuencos se observa en ambas caras, mientras que en tinajas y ollas subglobulares de perfil evertido solo en algunas secciones de superficies externas y en algunos casos en la parte interna de bordes. El cepillado se habría practicado mientras la pieza no se hallaba completamente seca, o en un evento posterior, antes de los tratamientos superficiales secundarios (Balfet et al., 1992).

Por último, destacamos la escasa presencia de la técnica de raspado (42 UA), advertido principalmente en cuencos y piezas indeterminadas. Se evidencia a partir de marcas de arrastre en dirección principalmente horizontal al recipiente. Si bien en ocasiones suele confundirse con el cepillado, se diferencia de éste a partir de la presencia de rebabas que suelen quedar por remoción de la pasta de las paredes superficiales, además de marcas -líneas- más profundas (Figura 7D). Esta tarea, la cual elimina irregularidades más gruesas de la pared de la vasija y genera un afinamiento de la misma, habría sido efectuada en estado plástico o cuero mediante algún instrumento de filo (Rye, 1981).

\section{Técnicas de tratamiento de superficie secundarias}

En cuanto a los tratamientos de superficie secundarios (Tabla 3 ) destacamos primeramente el pintado (99 UA) por sobre las demás técnicas. Esta técnica decorativa se registra en todo tipo de forma, aunque fundamentalmente en cuencos. Asimismo, se advierte exclusivamente en las superficies externas de las piezas o en ambas caras para algunos cuencos, platos y recipientes indeterminados. Los rastros de pintura, aplicados sobre la pared natural cerámica y fundamentalmente en tonalidad negra -aunque también hay roja y blanca-, se reconocen extendidos a través de la pared superficial de la vasija mediante líneas paralelas que evidencian la utilización de alguna herramienta con punta flecada -pincel-, aunque en ocasiones no pueden distinguirse dado un pulido posterior para 

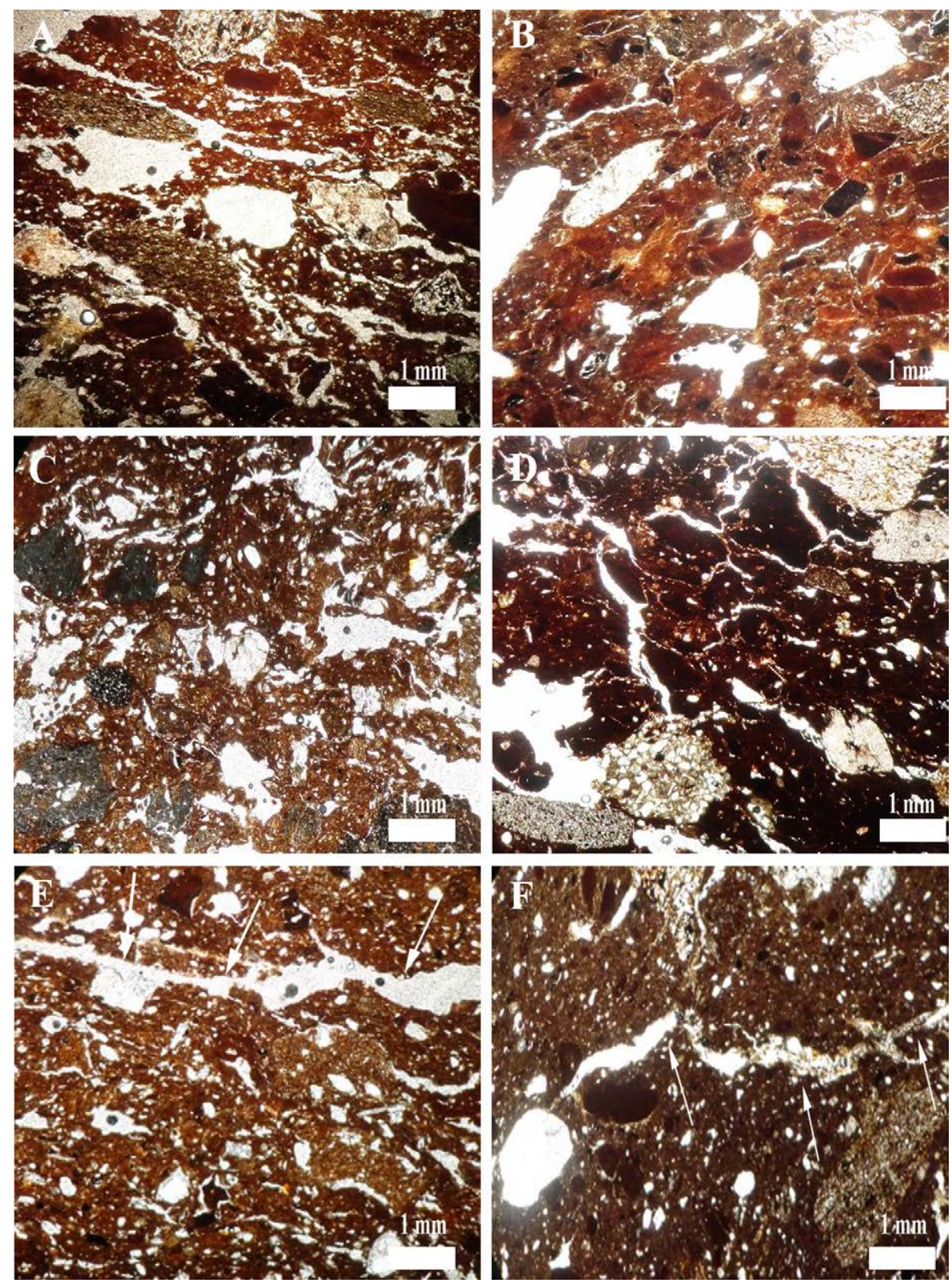

Figura 6. Fotomicrofotografía de secciones delgadas paralelas y perpendiculares a los recipientes que registran evidencias de técnicas primarias y secundarias (observación con nicoles paralelos). A, $B)$ cuerpos de olla globular de perfil evertido (A) y cuenco subglobular (B), se observa orientación paralela y subparalela de antiplásticos y cavidades elongadas - probable utilización de técnica de rodeteado (láminas delgadas paralelas); $C, D$ ) cuerpos de olla globular de perfil invertido (D) y tinaja (C), se observa orientación aleatoria y subparalela de antiplásticos y cavidades elongadas y rondasprobable utilización de técnica de rodeteado y presión de pared por técnica de pellizcado (láminas delgadas perpendiculares); E, F) cuerpos de cuenco subglobular (E) y olla globular de perfil evertido (F), se observan microfracturas que atraviesan la sección delgada (flechas) y la orientación aleatoria de antiplásticos y cavidades elongadas y rondas - probable área indicativa de superposición de rodetes (láminas delgadas perpendiculares).

emparejar el trazado (Figura 7E). Asimismo, se identifica una multidireccionalidad en la aplicación como gesto técnico. Por otro lado, también se evidencia el pintado mediante la técnica del goteado o salpicado, efectuado al rociar con algún instrumento -posiblemente pincel-, desde cierta distancia, sobre la cara superficial exclusivamente en cara interna de cuencos-. En muchas de las vasijas se advierte un desgastado y desleimiento de la pintura, y no un descascarado, lo cual podría implicar que las piezas fueron tratadas antes de ser cocinadas, probablemente en estado seco (Tite et al., 1998). 



Figura 7. Fotografías de evidencias de técnicas secundarias de manufactura. Tratamientos primarios de superficies. A) fragmentos de cuerpo y borde de cuenco subglobular que registra la técnica del alisado; B) fragmentos de cuerpo y borde de cuenco subglobular que registra alisado tosco; C)

fragmentos de cuerpo de cuenco globular que registra la técnica del alisado/cepillado (flechas); D) fragmentos de borde de olla globular de perfil evertido que exhibe la técnica del raspado (flechas). Tratamientos de superficie secundarios; E) Unidad de Análisis correspondiente a olla globular de perfil invertido que muestra la técnica del pintado; F) fragmento de cuerpo de tinaja en la que se evidencia el bañado (tonalidad blanca o ante); G) fragmento de cuerpo de cuenco subglobular en el que se evidencia la técnica del pulido (y pintado); H) fragmento de cuerpo de cuenco subglobular en el que se registra la técnica del exciso. Fabricación y aplicación de elementos de prensión; I, J) fragmentos de asas acintadas de tinaja (I) y olla globular (J) en el que se registran los cilindros de masa arcillosa -que se insertan en la pared superficial y se remachan-y el recubrimiento de los mismos con pasta para otorgar mayor agarre y fuerza; $K, L$ ) fragmentos de asa tipo mamelón de tinaja $(K)$ y cuenco subglobular $(L)$ en los que se advierte el pegado y arrastrado de la masa arcillosa en la pared hasta conformar la forma definitiva; $M, N, O$ ) fragmentos con pastillaje cerámico pegados y alisados en la superficie cerámica: rollo de pasta en zig-zag exciso en borde de cuenco globular $(M)$, rollo de pasta horizontal exciso en borde de cuenco subglobular $(N)$, rollo de pasta en media luna - posible "ceja" de figura antropomorfa-. 
Otro de los tratamientos secundarios de superficie registrados que implican el agregado de pigmento a los recipientes es el bañado (9 UA). La técnica se exhibe por el rastro de un baño líquido de tonalidad blanquecina, crema o ante, aplicado regularmente en la cara externa de las piezas, fundamentalmente tinajas y ollas. Si bien no se advierte la presencia de pinturas por encima de este pigmento diluido, se trata de vasijas incompletas por lo que no se descarta su presencia. La distribución del bañado no se reconoce claramente esparcida, por lo que el tratamiento habría consistido en el sumergimiento del recipiente en algún receptáculo en donde se ubicaba el diluido. Sin embargo, y dado que se registran en algunas cerámicas la evidencia de huellas de múltiples líneas finas paralelas en dirección horizontal a la vasija, es probable que se haya aplicado un cepillado en una etapa posterior, cuando el baño se hallaba fresco (Figura 7F). Asimismo, se advierte muchas veces desgastado, casi borrado, lo cual podría ser un indicador de que el procedimiento se haya ejecutado cuando la pieza se hallaba en estado "cuero" y antes de un segundo secado y su final cocción (Rye, 1981).

En baja proporción se destaca el pulido como técnica final de tratamiento de superficie cerámica (7 UA). Solo ha podido evidenciarse fundamentalmente en fragmentos de bordes y cuerpos de UA correspondientes a cuencos y platos. El procedimiento se reconoce a partir de tenues surcos perceptibles al tacto y/o visibles en las caras externas e internas de los recipientes. El pulimiento fue aplicado de manera intensa y constante, luego de un alisado y/o pintado, y se exhibe generalmente de forma pareja y paralela al recipiente (Figura 7G). Fue logrado mediante la utilización de alguna herramienta como roca, cuero o madera, otorgando un cierto brillo en la superficie cerámica y la eliminación de asperezas propias de la pasta. Dadas las características mencionadas, este tratamiento se habría efectuado durante un estado en el que la vasija se hallaba prácticamente seca (Rye, 1981). Finalmente se identifica el exciso, técnica que se registra en fragmentos de cuerpo pertenecientes a cuencos (6 UA). Se exhibe por los surcos excavados en la pared superficial de las paredes cerámicas, originando una cara plano contrastada (Figura 7H). Normalmente este tratamiento de remoción de materia arcillosa se ejecutó en forma de líneas paralelas de aproximadamente $3 \mathrm{~mm}$ de ancho, cuando la pasta se halla en estado cuero, antes del secado y con dirección paralela al recipiente (Balfet et al., 1992).

\section{Fabricación y aplicación de elementos de prensión}

La inserción de elementos abarca predominantemente la incorporación de asas a los recipientes (Tabla 2). Dentro de ellas destacamos por un lado fragmentos de asas dobles acintadas -a veces con forma de trenza- y remachadas $(n=62)$, reconociéndose normalmente en ollas y tinajas, con un espesor promedio de $2 \mathrm{~cm}$. Las asas fueron fabricadas aparte, siendo la mayoría de ellas un cilindro de pasta colocadas en posición horizontal al recipiente y luego remachadas en la parte interna. Estas inserciones se advierten en bultos en la superficie interna de los recipientes o en oquedades con restos de rebabas en las paredes, las cuales luego se deforman y originan fracturas. Antes del encaje de este tipo de asa se realizó una perforación y extracción de pasta de la pared de la vasija, mediante algún instrumento con punta, mientras la pieza todavía conservaba humedad (García Rosselló, 2013). Luego de insertadas, se remachó en la cara interna del recipiente mediante un aplastado, además de que en la sección ubicada en la cara externa el asa se recubrió con pasta, dándole mayor volumen, fuerza de agarre y mejor pegado a la pared del recipiente, evitando posibles filtraciones (Figura 7I, J).

Por otro lado se hallan fragmentos de asas adheridas $(\mathrm{n}=90)$, en forma de mamelón o apéndice, con tamaños variables aunque normalmente son pequeños, con espesor promedio de $2 \mathrm{~cm}$. Estas fueron pegadas a la pared de recipientes -cuencos- en su sección media y bordes, mediante una presión y luego alisadas (Figura $7 \mathrm{~K}, \mathrm{~L}$ ). En algunos casos se han registrado con decoración en pintura, surcos producto de excisiones o líneas de incisiones. 
Finalmente, se destaca la presencia en pocos tiestos de la adición de masa arcillosa o pastillaje $(\mathrm{n}=10)$ en forma de medialuna, rollos dispuestos en zig-zag $\mathrm{u}$ horizontales $\mathrm{y}$ otros que se corresponden fundamentalmente con la decoración de recipientes (Figura $7 \mathrm{M}, \mathrm{N}, \mathrm{O}$ ). Normalmente se ubican en sectores de cuerpo y borde de cuencos y poseen un espesor promedio de $1 \mathrm{~cm}$, aunque el largo varía considerablemente dependiendo de la forma. El pastillaje en forma de medialuna se vincula con la representación de caras antropomorfas y ostenta un relieve suave, sin rebabas y sin huellas claras en la zona de unión con la pared superficial, lo que indica un claro emparejamiento y afinamiento de la masa y un alisamiento posterior al pegado, muy probablemente durante el estado plástico o "cuero" de la pieza. Los rollos en zig-zag u horizontales se encuentran alisados y excisos, con canaladuras internas de $3 \mathrm{~mm}$ y se ubican en fragmentos de cuerpo, aunque no nos es posible saber su extensión dado que las piezas se hallan incompletas. Esta técnica solo fue observada en 5 UA.

\section{Discusión}

El estudio de trazas en superficies y cortes frescos de recipientes y de petrografía cerámica constituyeron una complementación efectiva para acercarse al conocimiento sobre las técnicas de manufactura de la alfarería de la Tambería de Guandacol. Sin embargo, nuestro registro y los métodos implementados para su análisis poseen sus limitaciones y no permiten obtener una reconstrucción global de esta etapa de la cadena operativa alfarera. En primer lugar, al ser muy fragmentaria la muestra no se pudo reconocer completamente las trazas en cada UA. Los mejores resultados se obtuvieron en la observación de fragmentos de mayores tamaños, con todas las partes de recipientes -base, cuerpo, borde- y con un alto grado de reconstrucción mediante remontaje. Por otro lado, la determinación de trazas originadas por las técnicas primarias muchas veces se dificultó, ya sea por la aplicación de técnicas secundarias, el uso de herramientas diferentes, la variación en la presión ejercida por el/la alfarero/a y la cocción de las piezas, entre otros factores. Hay que considerar además que las trazas pueden ser la consecuencia de diversos procesos de modelado (García Rosselló, 2013; Ottalagano, Brancatelli, Darigo, Iannelli y Pereyra, 2015). Asimismo, la observación petrográfica de láminas delgadas perpendiculares y paralelas al recipiente no siempre permitió reconocer los rasgos característicos y típicos mencionados en diferentes estudios sobre las técnicas implementadas y terminaron brindando información parcial y aproximada. Esta complicación puede deberse a los procedimientos secundarios, a la vez que el lugar en donde se realizó el corte delgado no siempre se efectúa en el área ideal -unión entre rodetes, puntos de inflexión entre las partes de recipiente- (De La Fuente, 2015; Rye, 1981; Woods, 1985).

Para profundizar el conocimiento sobre el levantado de recipientes y los gestos técnicos de manera más detallada e identificar particularidades en la producción de las diversas formas, es necesario utilizar piezas lo más completas posible y, en caso de que no sea viable, lograr la formación de UA altamente representativas de la vasija. Asimismo, será preciso complementar estos análisis con la utilización de las imágenes radiográficas así como con estudios experimentales.

Más allá de estas restricciones, el estudio nos permitió determinar una homogeneidad general en la elección de las técnicas primarias y secundarias de manufactura para las diferentes formas de recipientes de la Tambería. Entre las primarias más frecuentes se destaca el reodeteado o técnica de superposición de rodetes, la cual se detectó fundamentalmente mediante la observación de diversas trazas en la superficie -surcos, grietas, diferencias de espesor, entre otros- y en láminas delgadas -orientación parcial de cavidades y antiplásticos en cortes paralelos a la vasija y grietas entre rollos en secciones perpendiculares-. Los rodetes de pasta fueron colocados de forma horizontal para 
luego estirarlos, aplastarlos y arrastrarlos de manera manual, utilizando probablemente un molde de soporte que generaba bases normalmente uniformes, así como otras herramientas. También registramos las técnicas de engrosamiento de bases y bordes mediante el añadido de arcilla tanto en fracciones como en placas -bases de tinajas y ollas- y el estiramiento de masa y pellizcado, sea para la conformación de bases de diversos recipientes como para levantar paredes de cuencos subglobulares pequeños y platos, evidenciado en trazas - principalmente líneas de arrastrado verticales- y en secciones delgadas -orientación aleatoria de cavidades y antiplásticos en cortes paralelos a la vasija-. De cualquier manera, las evidencias indican que es muy probable que las técnicas hayan sido combinadas e intercaladas a lo largo del proceso de levantado de cuerpos cerámicos, ya sea para homogeneizar y alzar las paredes como para extender y acomodar los rollos superpuestos. Se ha reconocido en diversos estudios etnográficos (Arnold, 1972; Courty y Roux, 1995; García Roselló, 2011; Livingstone Smith, 2007; Rye, 1981; entre otros) que el rodeteado en verdad es un conjunto de técnicas muy versátil, que se fusiona con otros tratamientos como el paleteado, el estiramiento de masa y pellizcado, etc.

Otro aspecto que reveló la observación de trazas es el levantado de vasijas por partes, principalmente para aquellas de gran porte como las tinajas, ollas globulares de perfil evertido y posiblemente cuencos globulares y subglobulares grandes. En algunos recipientes pudieron reconocerse marcas de unión de segmentos, variaciones de espesor entre bases y cuerpos, agregado de arcilla y engrosado de bordes y bases. Esto implicaría una sucesión de etapas dentro de este momento de la cadena operativa alfarera, así como una diversidad de tareas entre ellas, respetando los tiempos de secado lógicos que demandan los recipientes -y sus partes- para poder ser levantados: por ejemplo, mientras se seca la base de una gran olla se pueden realizar otras tareas como armar el cuerpo superior, confeccionar otras bases, finalizar procedimientos secundarios de manufactura en demás recipientes, etc. Esto ha sido registrado en numerosos trabajos etnográficos (Druc, 2011; Gosselain y Livingstone Smith, 1995; Joffré, 2008; entre otros), lo cual refleja la complejidad de la fase operativa, en la elección de procedimientos que no necesariamente deben ser seguidos de forma diacrónica, sino más bien realizados a la par en muchos casos.

En cuanto a las técnicas secundarias de manufactura, los tratamientos de superficie primarios muestran una preeminencia del cepillado, el alisado y el alisado tosco, a veces en combinación con otras técnicas como el raspado -escasamente observado-. Los tratamientos son más regulares en piezas pequeñas y medianas -platos, cuencos globulares y subglobulares pequeños y ollas globulares de perfil invertido-, existiendo una buena cantidad de recipientes de gran porte sin un completo tratamiento. Las marcas de alisamiento y cepillado son generalmente bien perceptibles en el registro, a pesar del proceso de desgastado natural por factores postdepositacionales. Los tratamientos de superficie secundarios, vinculados a la decoración, son escasos en el registro, destacándose el agregado de pigmento mediante la técnica del pintado por sobre las otras -bañado, pulido, exciso-. Las trazas de pintura - principalmente negraparecen presentarse de manera prácticamente uniforme en caras superficiales internas/ externas de cuencos y externas de ollas, a través del arrastre multidireccional de pinceles y del salpicado. Finalmente, también existe una gran regularidad en la fabricación y aplicación de elementos de prensión, ya sea mediante la inserción de asas dobles acintadas, remachadas para tinajas y ollas o la adhesión de mamelones y de pastillaje para cuencos. Estos tratamientos se reconocen adecuadamente implementados y cuidados en sus terminaciones, aunque el pastillaje constituye una técnica que se exhibe en fragmentos muy aislados, lo que imposibilita un claro conocimiento de su aplicación.

Por otro lado, los gestos técnicos, vinculados a los movimientos, posiciones y herramientas, fueron parcialmente identificados. Si bien el arrastre de materia con 
dirección vertical y oblicua para la conformación de algunas bases y paredes de platos y cuencos, y la orientación multidireccional de los alisados/cepillados, y paralelo del pulido, son muestras claras de una uniformidad gestual por parte de los/as alfareros/as para el conjunto global, el estado fragmentario del registro imposibilita su conocimiento.

Todos estos datos permiten entender que los recipientes del registro de la Tambería presentan una elaboración básica muy similar para cada parte de su estructura -base, cuerpo, borde-, así como formas homogéneas -dentro de la diversidad existente en cada categoría-, lo que implica un trabajo alfarero tendiente a la consecución de un producto uniforme, con secuencias de fabricación relativamente formales. No se reconocen variaciones profundas en la secuencia del levantado más que la falta y/o irregularidad en la aplicación de ciertos tratamientos de superficies primarios. Esto podría deberse a múltiples factores, como las propiedades de la pasta, el tiempo de secado y otros rasgos tecnológicos, o también a aspectos funcionales -obtener mayor superficie de contacto y agarre para traslados, otorgar más permeabilidad con el cepillado-, y/o estilísticas - lograr relieves y mejor adherencia para el posterior acabado de superficie al añadir pinturas y engobes- (Rice, 1987; Skibo, 1992). Sin embargo, pensamos que más bien es el reflejo de una cierta variabilidad en la destreza y experiencia técnica de diversos alfareros/as comunitarios en la producción (García Rosselló, 2013; Lemonnier, 1992).

En contextos de desarrollo económico y demográfico, con amplia demanda de productos y alimentos en la Tambería y en los núcleos habitacionales cercanos, como el que se plantean hasta el momento para el Valle de Guandacol durante el Tardío y la época de dominación Incaica (Bárcena, 2010; Bárcena et al., 2010; Carosio, 2015; Iniesta y Bárcena, 2014), la trasferencia de saberes técnicos estaría a cargo de ceramistas con diverso grado de pericia en la fabricación pero imbuidos de lineamientos que responden a una herencia manufacturera común. El traspaso de los conocimientos técnicos normalmente se origina en la interrelación próxima entre artesanos, lo que posibilita la transmisión de los esquemas motrices precisos para lograr la instrucción relacionada con el levantado de la cerámica. Mediante la práctica reiterada y cotidiana de la actividad, las elecciones y gestos técnicos llegan a ser paulatinamente incluidos inconscientemente por el/la alfarero/a (Gosselain, 2000). Sin embargo, este proceso debe entenderse en un marco más amplio, comunitario, en donde se ceden y combinan conocimientos tecnológicos con otros aprendizajes y valores sociales, éticos e identitarios (Calvo Trias y García Rosselló, 2011).

Creemos que esta tradición fuertemente arraigada en Guandacol se habría nutrido de conocimientos tecnológicos de otras producciones previas y contemporáneas de la región Valliserrana, especialmente el sur. Las técnicas mencionadas han sido utilizadas en alfarerías diversas del Noroeste Argentino a lo largo de sus etapas cronológicas (Balesta, Zagorodny y Valencia, 2009; López, 2011; Pérez, 2013; Pérez Pieroni, 2015; Wyndveldt, 2008; entre otros). Para las piezas Sanagasta/Angualasto de la región, Boman (1927-1932) destaca su confección en el norte del actual La Rioja mediante rodetes en base a rastros visibles en las superficies cerámicas. De La Fuente (2011b, 2015), de acuerdo a estudios de trazas y radiográficos en Batungasta e inmediaciones, establece para recipientes de este estilo la fabricación por partes de las vasijas, la utilización de la técnica de rodeteado, la aplicación del raspado y paleteado -técnica hasta ahora no determinada en nuestro registro- para afinar las paredes, el uso de molde para la conformación de las bases, el estiramiento de masa para bases planas y cónicas, y el modelado manual para tipo "pie de compotera". Feely (2013) señala para las piezas de diversos sitios de Fiambalá-Abaucán el mismo tipo de técnicas primarias, la formación de bases con moldes y la preferencia por alisados y escasamente el pulido como técnicas de tratamiento de superficie primario. Varela (2005) indica para piezas del norte de San Juan la fabricación en base a la unión de rollos hasta alcanzar el mayor diámetro y luego concluir con placa o cinta en el borde del recipiente. 
Este punto es interesante y deberá profundizarse, ya que normalmente las técnicas de levantado suelen tener un conocimiento más restringido en el grupo, son más difíciles de modificar en el tiempo al estar menos visibles, a diferencia de otros rasgos como las decoraciones y las formas cerámicas, están más expuestos a préstamos, influencias y a la innovación al estar más perceptibles y condicionados por intereses políticos/ económicos, ejercicio de dominio, etc. (Calvo Trías y García Rosselló, 2011; Mahias, 1993; Petrequin y Petrequin, 1999). Esto podría ser un indicador de un fuerte vínculo social regional del sur Valliserrano en el proceso productivo, con un sustrato común de considerable acervo de conocimientos sobre la tecnología alfarera, durante un extenso periodo de tiempo y sin delimitación profunda en las relaciones entre los individuos de los grupos sociales.

\section{Consideraciones finales}

En contextos arqueológicos donde el registro alfarero se presenta altamente fragmentado, el estudio sobre las técnicas de manufactura constituye un problemática compleja. Es por ello que es necesaria una combinación de diferentes métodos de observación para lograr los mejores acercamientos, además de una buena ordenación del registro y el remontaje de tiestos.

Se considera que la imposibilidad de reconocer completamente las técnicas de manufactura no implica necesariamente su ausencia, ya que muchas de las trazas formadas en el producto final y las características de las pastas cerámicas pudieron ser eliminadas y/o desfiguradas por otros procedimientos posteriores. De igual modo, una misma traza puede identificar más de una ejecución. Los mejores resultados se obtienen cuando un proceso tecnológico logra advertirse por más de una traza y por la regularidad de su aplicación.

Se trata de una temática escasamente abordada en los estudios ceramológicos del NOA y ausente en el oeste riojano. Desde de la reconstrucción de la tecnología cerámica se puede acercar a las estrategias de aprendizaje, la práctica cotidiana, la relación entre los agentes sociales, el ambiente y el contexto económico y político que condiciona la producción alfarera. En otras palabras, se puede examinar las dinámicas sociales de los grupos humanos. En este sentido, este trabajo ha buscado poner en valor la importancia de este tipo de estudios y acumular información respecto a la tecnología cerámica de la Tambería, los modos de producción dentro de la comunidad durante los tiempos prehispánicos y su vínculo regional. Si bien el registro estudiado presenta limitaciones importantes, se consideran algunas apreciaciones a modo de reflexión.

Se entiende que en Guandacol durante los Desarrollos Regionales y muy probablemente en etapas posteriores existió una tradición tecnológica alfarera manifestada en el estilo Sanagasta/Angualasto con ceramistas que implementaron técnicas de manufactura uniformes, basados en un alto nivel de interrelación entre personas o ideas que originaría idénticas maneras de levantar recipientes, en contextos de aprendizaje comunes. Sin embargo, es factible la existencia de múltiples alfareros/as, con diversa pericia y experiencia técnica, dentro de un modelo de producción doméstica familiar y comunitaria. Todo ello en el marco de un desarrollo demográfico y crecimiento económico propio del valle durante el periodo.

Todos los resultados y sus interpretaciones deberán ser contrastados en futuras labores, ampliando el estudio del registro alfarero, incorporando nuevas técnicas analíticas y comparando con la información desprendida de las investigaciones regionales. 


\section{Agradecimientos}

A las instituciones que financiaron y posibilitaron nuestras labores en Guandacol: ANPCyT, CONICET y UNCUYO. Al gobierno de La Rioja y del departamento de Felipe Varela y a la comunidad del pueblo de Guandacol. A Roberto Bárcena (CONICET) y a Amancay Martínez (UNSL). A María José Ots (CONICET-UNCUYO). A quienes participaron en las tareas de campo y laboratorio, Lourdes Iniesta, Juan Pablo Aguilar, Silvia Storoni, Lourdes Murri, Michelle Lacoste, Vanina Terraza y Cristian Tivani (CONICET-UNCUYO). A los evaluadores de este trabajo por sus sugerencias y comentarios. 


\section{Q Referencias citadas}

"Albero Santacreu, D. (2014). Materiality, Techniques and Society in Pottery Production. The Technological Study of Archaeological Ceramics through Paste Analysis. Warsaw/Berlin: De Gruyter Open Ltd.

》Arnold, D. (1972). Native pottery making in Quinua, Perú. Antropos, 67, 858-872.

» Balesta, B., Zagorodny, N. y Valencia, C. (2009). Evidencias de estandarización en la manufactura de cuencos de La Aguada Orilla Norte (Argentina). Estudios Atacameños, 37, 79-98.

» Balfet, H., Fauvet-Berthelot, M. F. y Monzón, S. (1992). Normas para la descripción de vasijas cerámicas. México DF: Centro de Estudios Mexicanos y Centroamericanos (CEMCA).

"Bárcena, J. R. (2010). Investigaciones arqueológicas en la Tambería de Guandacol (Departamento Felipe Varela, La Rioja). En R. Bárcena (Ed.), Aportes de las IV Jornadas Arqueológicas Cuyanas, XAMA Monografías 2 (pp. 121-181). Mendoza: Instituto de Ciencias Humanas Sociales y Ambientales (INCIHUSA), CONICET

» Bárcena, J. R., Carosio, S. A. e Iniesta, M. L. (2010). La Tambería de Guandacol y el registro arqueológico de vestigios de las poblaciones locales del período de Desarrollo Regionales y de dominación Inka. Síntesis de los análisis e interpretación de la arquitectura y cerámica. En J. R. Bárcena y H. Chiavazza (Eds.), Arqueología Argentina en el Bicentenario de la Revolución de Mayo. XVII Congreso Nacional de Arqueología Argentina 4 (pp. 1649-1654). Mendoza: Instituto de Ciencias Humanas Sociales y Ambientales (INCIHUSA), CONICET

" Bennett, W., Bleiler, E. y Sommer, F. (1948). Northwest Argentine Archaeology. Yale University Publications in Anthropology, 38, 32-64.

» Boman, E. (1927-1932). Estudios arqueológicos riojanos. Anales del Museo Nacional de Historia Natural, 35(72), 1-341.

" Calvo Trias, M. y García Rosselló, J. (2011). Tradición técnica y contactos: Un marco de reflexión centrado en la producción cerámica. Rubicatum, 5, 1-9.

»Callegari, A. y Gonaldi, M. E. (2007-2008). Guandacol. Estructuras arquitectónicas tardías del sudoeste de la Provincia de La Rioja. Arqueología, 14, 173-187.

"Canals Frau, S. (1953). Las poblaciones indígenas de la Argentina. Su origen, su pasado, su presente. Buenos Aires: Sudamericana.

"Capitanelli, R. (1992). Los Ambientes naturales del territorio argentino. En J. Roccatagliata (Ed.), La Argentina. Geografía general y marcos regionales (pp. 73-143). Buenos Aires: Planeta.

"Carosio, S. A. (2015). Investigaciones ceramológicas en el oeste de la Provincia de La Rioja: La Tambería de Guandacol y el periodo de los Desarrollos Regionales (1000-1470 AD). (Tesis Doctoral inédita), Universidad Nacional de Córdoba, Argentina.

»Carosio, S. A., Aguilar, J. P. y Bárcena, J. R. (2013). Reconstrucción 3D y cálculo volumétrico de recipientes cerámicos. Alcances y limitaciones para el estudio y conservación cerámica de la Tambería de Guandacol (Provincia de La Rioja). La Zaranda de Ideas, 9(2), 57-76.

"Carosio, S. A., Iniesta, M. L.y Bárcena,J.R. (2011). Análisis ceramológicos de la Tambería de Guandacol (Dpto. Felipe Varela, Provincia de La Rioja). Avances para la conformación de grupos de referencia y el conocimiento tecnomorfológico de recipientes. Comechingonia Virtual, 2(5), 98-128. 
» Carr, C. (1993). Identifying individual vessels with X-radiography. American Antiquity, 58(1), 96-117.

»Cremonte, M. B. (2006). El estudio de la cerámica en la reconstrucción de las historias locales. El sur de la quebrada de Humahuaca (Jujuy, Argentina) durante los Desarrollos Regionales e Incaico. Chungara. Revista de Antropología Chilena, 38(2), 239-248.

»Courty, M. A. y Roux, V. (1995). Identification of Wheel Throwing on the basis of Ceramic Surface Features and Microfabrics. Journal of Archaeological Science, 22(1), 17-50.

»Debenedetti, S. (1917). Investigaciones arqueológicas en los valles preandinos de la Provincia de San Juan. Revista de la Universidad de Buenos Aires, Publicaciones de la Sección Antropológica 15, XXXII, 61-90 y XXXIV, 226-256.

»De Aparicio, F. (1936). Vestigios de caminos incaicos en la provincia de La Rioja. Revista de Geografía Americana, 36(6), 167-174.

»De La Fuente, G. (2011a). Chaine operatoire, technical gestures and pottery production at southern Andes during the Late Pediod (c. AD 900 - AD 1450) (Catamarca, Northwestern Argentina, Argentina). En S. Scarcella (Ed.), Archaeological Ceramics: A Review of Current Research (pp. 89-102). Oxford: BAR International Series 2193, Archaeopress.

»De La Fuente, G. (2011b). Urns, Bowls, and Ollas: Pottery-Making Practices and Technical Identity in the Southern Andes During the Late Period (ca. A.D. 90o-A.D. 1450) (Catamarca, Northwestern Argentine Region, Argentina). Latin American Antiquity, 22(2), 224-252.

» De La Fuente, G. (2015). Técnicas de manufactura cerámica durante el Período Tardío: una aproximación a través de la radiografía industrial y la petrología cerámica (Tinogasta, Catamarca, Argentina). Cuadernos del Instituto Nacional de Antropología y Pensamiento Latinoamericano, 24(1), 1-20.

»De La Fuente, N. (1973). El Yacimiento Arqueológico de Guandacol, Provincia de la Rioja. Revista del Instituto de Antropología, 4, 151-167.

»Dobres M. y Hoffman, C. (1994). Social Agency and the Dynamics of Prehistoric Technology. Journal of Archaeological Method and Theory, 1(3), 211-258.

»Druc, I. (2011). Tradiciones alfareras del valle de Cajamarca y cuenca alta del Jequetepeque, Perú. Boletín del Instituto Francés de Estudios Andinos, 40(2), 307-331.

» Feely, A. (2013). Los modos de hacer vasijas: elecciones técnicas y estilos tecnológicos del oeste tinogasteño (Catamarca). En N. Ratto (Ed.), Delineando prácticas de la gente del pasado. Los procesos socio-históricos del oeste tinogasteño (Catamarca) (pp. 69-130). Buenos Aires: Sociedad Argentina de Antropología.

» Gambier, M. (2000). Prehistoria de San Juan. Ansilta: San Juan.

» García Rosselló, J. (2011). Modelado, aprendizaje y espacio social: Una reflexión desde la tecnología cerámica. Werken, 14, 63-74.

» García Rosselló, J. (2013). Análisis arqueológico de las macrotrazas de manufactura: Las vasijas cerámicas del poblado del Puig de Sa Morisca (Mallorca, siglo IV A.C.). Bolletin de la Societat Arqueològica Lul.liana, Revista d'Estudis Històrics, 69, 43-64.

»Garrote J. y Callegari, A. (1996). Análisis macro y microscópico realizado a las colecciones cerámicas de Guandacol y los Milagros. En H. Lagiglia (Ed.), Actas y Memorias del XI Congreso Nacional de Arqueología, Revista del Museo de Historia Natural, 25, (1/4) (pp. 203-223). San Rafael: Museo de Historia Natural de San Rafael.

" Gibbs, K. (2008). Understanding community: A comparison of three late Neolithic pottery assemblages from Wadi Ziqlba, Jordan. (Tesis Doctoral inédita), Universidad de Toronto, Canadá. 
» González, A. y Pérez, J. (1972). Argentina indígena. Vísperas de la conquista. Buenos Aires: Paidós.

» González de Bonaveri, M. I., Frére, M M. y Solá, P. (200o). Petrografía de cerámicas arqueológicas en la cuenca del río Salado, provincia de Buenos Aires. Relaciones de la Sociedad Argentina de Antropología, XXV, 207-226.

» Gosselain, O. (1992). Technology and Style: Potters and Pottery among Bafia Cameroon. Man, 27(3), 559-586.

» Gosselain, O. (2000). Materializing identities: an African perspective. Journal of Archaeological Method and Theory, 7(3), 187-217.

" Gosselain, O. y Livingstone Smith, A. (1995). The Ceramic and Society Project: An ethnographic and experimental approach to technological style. En A. Lindhal y O. Stilborg (Eds.), The Aim of Laboratory Analysis in Archaeology (pp. 147-160). Stockholm: KVHAA Konferenser 34.

» Iniesta, M. L. y Bárcena, J. R. (2014). Investigaciones arqueológicas sobre las sociedades tardías del valle de Guandacol (Departamento Felipe Varela, oeste de La Rioja): Espacio, estilos tecnológicos cerámicos y cronología. Arqueología, 20, 61-82.

» Joffré, G. (2008). Producción alfarera en Piura (Perú): estilos técnicos y diacronía. Boletín del Instituto Francés de Estudios Andinos, 37(3), 477-509.

» Lechtman, H. (1977). Style in technology. Some early thoughts. En H. Lechtman y R. Merrill (Eds.), Material culture. Style, organization, and dynamics of technology. 1975. Proceedings of the American Ethnological Society (pp. 3-20). Nueva York: West Publishing Co.

» Lemonnier, P. (1992). Elements for an Anthropology of Technology. Michigan: Anthropological Papers 88, Museum of Anthropology, University of Michigan.

» Leroi-Gourhan, A. (1964). Le geste et la parole I: Technique et langage. Paris: Albin Michel.

» Livingstone-Smith, A. (2007). Chaîne Opératoire de la Poterie, Références ethnographiques, analyses et reconstitution. Tervuren: Musée Royal de l'Afrique Centrale.

» López, M. (2000-2002). Técnicas de acabado de superficie de la cerámica arqueológica: indicadores macro y microscópicos. Una revisión sobre las técnicas de estudio más habituales. Cuadernos del Instituto Nacional de Antropología y Pensamiento Latinoamericano, 19, 347-364.

» López, M. (2011). De los estilos tecnológicos a las identidades de los alfareros. Propuesta teórica y metodológica para la identificación de distintos productores de piezas cerámicas consumidas en un mismo sitio arqueológico. Pacarina, 6, 55-69.

» López, M., Caramés, L. y Acevedo, V. (2010). El uso de rayos X en la conservación de cerámica arqueológica. Casos de estudio en Quebrada de Humahuaca, República Argentina. Ge-Conservación, 1, 221-234.

» Mahias, M. (1993). Pottery techniques in India. Technical variants and social choice. En P. Lemonnier (Ed.), Technological choices. Transformation in material cultures since the Neolithic (pp. 157-180). Londres: Routledge.

» Martineau, R. (2002). Etudes analytiques et expérimentales à Chalain et Clairvaux (Jura), entre 3200 et 2900 av.J.-C. Bulletin de la Société Préhistorique Française, 99(1), 150-153.

" Méndez, A. (2008). Observaciones y estudios experimentales sobre las deformaciones, características morfológicas y técnicas de la Cerámica Angualasto. Comechingonia Virtual, 3, 159-185.

» Middleton, A. (1997). Ceramic Petrography. Revista do Museu de Arqueologia e Etnologia, 2, 73-79. 
» Miller, D. y Tilley, M. (1996). Editorial. Journal of Material Culture, 1(1), 5-14.

» Orton, C., Tyers, P. y Vince, A. (1997). La Cerámica en Arqueología. Barcelona: Crítica.

»Ottalagano, F., Brancatelli, C., Darigo, M., lannelli, L. y Pereyra, B. (2015). Gestos técnicos, morfología y rastros de uso en la alfarería prehispánica del sitio La Palmera 2 (Provincia de Entre Ríos). Anuario de Arqueología, 7, 67-84.

"Pérez, M. (2013). Aproximación tecnomorfológica a los vasitos chatos de Doncellas (Puna Septentrional Argentina) a través de técnicas arqueométricas. Revista Española de Antropología Americana, 43(2), 385-404.

» Pérez Pieroni, M. J. (2015). Prácticas productivas y tradiciones tecnológicas: la manufactura cerámica prehispánica tardía y colonial en la cuenca sur de Pozuelos y el área de Santa Catalina, Puna de Jujuy, Argentina. Relaciones de la Sociedad Argentina de Antropología, XL(1), 13-44.

»Petrequin, A. y Petrequin, P. (1999). La poterie en Novelle Guinée: savoir-faire et trasmision des techiques. Journal de la Societé des Océaniestes, 108(1), 71-101.

»Puente, V. (2012). Lo que "oculta” el estilo: materias primas y modos de hacer en la alfarería Belén. Aportes desde la petrografía de conjuntos cerámicos del valle del Bolsón (Belén, Catamarca, Argentina). Estudios Atacameños, 43, 71-94.

» Revuelta, C., Carosio, S. A. y Aguilar, J. P. (2012). Formas y representaciones tardías. Aproximaciones a una mirada integral al estilo cerámico Sanagasta-Angualasto. Anales de Arqueología y Etnología, 65-66, 57-85.

» Rice, P. (1987). Pottery análisis: a sourcebook. Chicago: University of Chicago Press.

» Roux, V. y Courty, M. (1998). Identification of wheel-fashioning methods: technological analysis of 4 th-3rd millenium BC oriental ceramics. Journal of Archaeological Science, 25, 747-763.

" Rye, O. (1981). Pottery Technology: Principles and Reconstruction. Washington D.C.: Taraxacum.

» Sempé, M. C. (1977). Batungasta: un sitio tardío e incaico en el valle de Abaucán (Dpto. Tinogasta-Catamarca) significación etnohistórica. En H. Lagiglia (Ed.), Actas y Memorias del IV Congreso Nacional de Arqueología, Revista del Museo de Historia Natural 2 (1/4) (pp. 69-83). San Rafael: Museo de Historia Natural de San Rafael.

»Serrano, A. (1966). Manual de la Cerámica Indígena. Córdoba: Assandri.

»Shanks, M. y Tilley, C. (1987). Reconstructing Archaeology. Cambridge: Cambridge University Press.

»Sillar, B. (2009). The social agency of things? Animism and materiality in the Andes. Cambridge Archaeological Journal, 19(3), 367-377.

»Skibo, J. (1992). Pottery function. A use-alteration perspective. Nueva York: Plenum Press.

»Spengler, G. y Callegari, A. (2010). Manifestaciones del Período Tardío (850-1480 DC) en el Noroeste Riojano. En J. R. Bárcena (Ed.), Arqueología del Centro Oeste Argentino. Xama, Serie Monografías (pp. 233-252). Mendoza: Instituto de Ciencias Humanas Sociales y Ambientales (INCIHUSA), CONICET.

» Tarragó, M. (2000). Chacras y pukara. Desarrollos sociales tardíos. En M. Tarragó (Ed.), Nueva Historia Argentina 1: Los pueblos originarios y la conquista (pp. 257-300). Barcelona: Sudamericana.

» Tite, M. S., Freestone, I., Mason, R., Molera, J., Vendrell-Saz, M. y Wood, N. (1998). Lead glazes in antiquity. Methods of production and reasons for use. Archaeometry, 40(2), 241-26o. 
" van der Leeuw, S. (1993). Giving the potter a choice. Conceptual aspects of pottery techniques. En P. Lemmonier (Ed.), Technological choice: transformations in material cultures since the neolithic (pp. 238-288). Londres: Routledge.

»Varela, A. (2005). Cerámica Angualasto: Precisiones técnicas, formales e iconográficas y su vinculación con la cerámica del Norte Chico Chileno. Trabajo presentado en el III Taller Binacional Argentino-Chileno. Arqueología de La Cordillera de Los Andes, San Rafael.

»Woods, A. (1985). An introductory note on the use of tangential thin sections for distinguishing between wheel-thrown and coil/ring-built vessels. Bulletin of the Experimental Firing Group, 3, 100-114.

"Wynveldt, F. (2008). Tecnología cerámica Belén: caracterización macroscópica y conceptualización en la manufactura alfarera. Intersecciones en Antropología, 9, 157-172.

»Zagorodny, N., Morosi, M., lucci, M. E. y Wynveldt, F. (2010). Estudios composicionales de las pastas de cerámica tardía del valle de Hualfín (Belén, Catamarca). Arqueología, $16,125-149$. 